\title{
Phytochemical Studies on Linum Usitatissimum Seeds and the Nanoformulation of the Bioactive Butanol Extract
}

\author{
Fatma Mohamed El-Feky \\ Chemistry Department \\ Faculty of Science \\ Mansoura University \\ Egypt
}

\author{
Ibrahim M. El-Sherbiny \\ Center for Materials Science, \\ Zewail City of Science and \\ Technology, 6th October City, \\ 12588 Giza, Egypt \\ Mamdouh Abdel-Mogib \\ Chemistry Department \\ Faculty of Science \\ Mansoura University \\ Egypt
}

\author{
Manal Gmal El-Fedawy \\ Chemistry Department \\ Faculty of Science \\ Mansoura University \\ Egypt
}

\begin{abstract}
:
The phytochemical investigation of Linum usitatissimum, family Linaceae, resulted in the separation and identification of a lignane, 8-5' neolignan 1 (dehydrodiconiferyl alcohol-4- $\beta$-D-glucoside), in addition to identification of many compounds by the GC/MS technique. The antimicrobial activities of hexane, methylene chloride and butanol fractions were comparable to ampicillin. The activities against $E$. coli were $29.2 \%, 37.5 \%$, and $66.7 \%$, respectively; against S. aureus were $45.4 \%, 36.4 \%$ and $63.6 \%$, respectively, and against $C$. albicans were $26.9 \%, 46.1 \%$ and $73.1 \%$, respectively. Antioxidant activity was assessed by ABTS method. It decreased in the following order: ascorbic acid > butanol fraction > methylene chloride fraction $>$ hexane fraction. The cytotoxicity against HePG2 was found to be "moderate" for butanol and methylene chloride fractions, and "weak" for the hexane fraction. The cytotoxicity against MCF-7 was found to be "strong" for butanol fraction, and "weak" for both hexane and methylene chloride fractions. The lignane-rich subfraction, Lu 3d was incorporated into pluronic nano-micelles using nanoprecipitation technique through a modified procedure. The physicochemical characteristics of the developed Lu 3d-loaded nano-micelles such as particle size, potential and morphology were determined using DLS and HR-TEM. The average diameters of the prepared plain and Lu 3d-loaded pluronic nano-micelles were found to be $207 \pm 12$ and $225 \pm 18 \mathrm{~nm}$, respectively. The encapsulation of Lu 3d into nano-sized particles has enhanced their aqueous dissolution and consequently improved their bioavailability. Nanoformulation of Lu 3d led also to a stable colloidal dispersion with a strong green color, indicating its homogenous distribution in the aqueous medium at a significantly higher concentration than that obtained using other solvents.
\end{abstract}

Keywords: Linum usitatissimum; Linaceae; Flax; 8-5' neolignan; pluronic nano-micelles; controlled release. 


\section{INTRODUCTION}

Linum usitatissimum L., flaxseed or linseed, is one of the most ancient of cultivated crops [1] of the family Linaceae. It is a food and fiber crop that is grown in cooler regions of the world.Linaceae family includes approximately 250 species. There are 14 genera, classified into two subfamilies: Linoideae and Hugonioideae (often recognized as a distinct family, the Hugoniaceae). Flax was first domesticated in the Fertile Crescent region [2].

The agronomic value of the plant lies in the seeds; it has the ability to reduce the risk of definite diseases [3]. It contains nearly $38-40 \%$ fat, $23-25 \%$ proteins and $15-20 \%$ carbohydrates of which one quarter to one-third consisted of mucilage [4].

Flaxseed is the richest dietary source of lignans. The major flaxseed lignan, is secoisolariciresinol, in the form of secoisolariciresinol diglucoside. The phytochemical investigation of $L$. usitatissimum revealed the presence of steroids [5], flavonoids [6], lignans [7], phenolics [8] and fatty acids [9].

Various types of polymers have been utilized in many delivery systems as they can efficiently deliver the drugs and therapeutic agents to the target site in a controllable manner, and accordingly increase the therapeutic benefit, while minimizing the side effects [10].

In this article we have studied the phytochemical constituents of flax seeds and the biological activities of their extract fractions. The antimicrobial activities of the extract fractions were also assessed. Additionally, the bioactive butanol subfraction, containing lignans, was incorporated into pluronic nano-micelles and its controlled release profile was investigated.

\section{RESULTS AND DISCUSSION}

\subsection{Phytochemical evaluation}

The chromatographic separation of the dried aerial part extracts of Linum usitatissimum afforded $8-5^{\prime}$ neolignan (dehydrodiconiferyl alcohol-4- $\beta$-Dglucoside 1). The identity of which was established by comparing its $1 \mathrm{H}$ NMR data with the reported previously by $8-5^{\prime}$ neolignan (dehydrodiconiferyl alcohol-4- $\beta$-D-glucoside [11].

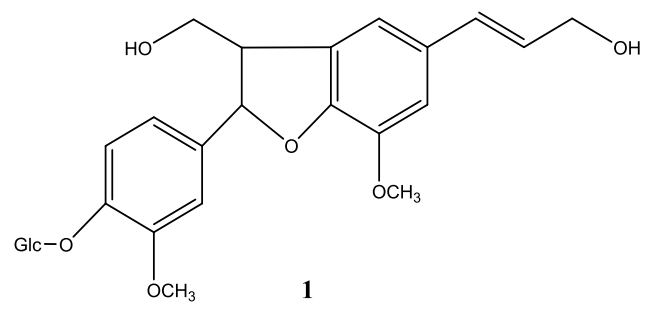

In addition, 60 compounds from acetogenins, terpenoids, steroids, and others were identified by the GC/MS (Table 4) from fractions of hexane Lu1, Lu3a and methylene chloride Lu2, Lu3b by comparing the MS spectra with those in NIST library. A sample from hexane fraction Lu1 afforded 24 compounds, representing 95.29\% from the sample, with 9,12,15-octadecatrienoic acid $(80.97 \%)$, hexadecanoic acid $(10.69 \%)$ and selegiline $(0.56 \%)$ being the major components. Methylene chloride fraction Lu2 afforded 24 compounds, representing $85.34 \%$ from the sample, with methyl $(\mathrm{Z}, \mathrm{Z}, \mathrm{Z}) 9,12,15$ octadecatrienoate (32.01\%), butyl 9,12,15octadecatrienoate $(16.29 \%)$ and methyl 9-cis,11trans-octadecadienoate $(7.69 \%)$ being the major components. Hexane extract Lu3a afforded 19 compounds, representing $75.41 \%$ from the sample, with methyl palmitate (38.64\%), methyl $(Z, Z) 7,10$ - methyloctadecadienoate $(9.91 \%)$ and methyl $(Z, Z) 8,11$-octadecadienoate $(9.85 \%)$ being the major components. Methylene chloride extract Lu3b afforded 14 compounds, representing 4.96\% from the sample, with tetracosane $(0.81 \%)$, eicosane $(0.61 \%)$, and hexacosane $(0.54 \%)$ being the major components (Table 4).

\subsection{Biological applications}

\subsubsection{Antimicrobial activity assessment}

In our current study, the antimicrobial potentials of hexane Lu1, methylene chloride Lu2, and butanol Lu3d extracts of $L$. usitatissimum were examined by disc diffusion assay method, using pathogenic microbial species; Staphylococcus aureus, representing Gram positive bacteria, Escherichia coli, representing Gram negative bacteria, and $C$. albicans, representing fungi (Table 1).

The activity index of hexane extract (Lu1), methylene chloride extract (Lu2) and butanol extract (Lu3d) against E. coli were comparable to ampicillin (29.2\%, 37.5\% and 66.7, respectively). 
The activity index of hexane extract (Lu1), methylene chloride extract (Lu2) and butanol extract (Lu3d) against $S$. aureus were comparable to ampicillin $(45.4 \%, 36.4 \%$ and $63.6 \%$, respectively). The activity index of hexane extract (Lu1), methylene chloride extract (Lu2) and butanol extract (Lu3d) against C. albicans were comparable to colitrimazole $(26.9 \%, 46.1 \%$ and $73.1 \%$, respectively) (Table 1 ). Shivani and his coauthors, 2013 reported the antimicrobial inhibitory effect of leaves and flowers methanolic extracts against six strains [12].

Table 1: The inhibition zone in $\mathrm{mm}$ and activity index\% of extracts of $L$. usitatissimum compared to standard antibiotics

\begin{tabular}{|l|l|l|l|l|l|l|}
\hline \multirow{2}{*}{ Fraction } & \multicolumn{2}{|c|}{ E. coli $(\mathrm{mg} / \mathrm{ml})$} & \multicolumn{2}{c|}{$\begin{array}{c}\text { S. aureus } \\
\text { (mg/ml) }\end{array}$} & \multicolumn{2}{c|}{$\begin{array}{c}\text { C. albicans } \\
\text { (mg/ml) }\end{array}$} \\
\cline { 2 - 8 } & $\begin{array}{c}\text { Diamet } \\
\text { er of } \\
\text { inhibitio } \\
\text { n zone } \\
\text { (in } \mathrm{mm})\end{array}$ & $\begin{array}{c}\text { \% } \\
\text { Activit } \\
\text { y index }\end{array}$ & $\begin{array}{c}\text { Diameter } \\
\text { of } \\
\text { inhibition } \\
\text { zone (in } \\
\mathrm{mm})\end{array}$ & $\begin{array}{c}\text { \% } \\
\text { Activity } \\
\text { index } \\
\text { er of } \\
\text { inhibitio } \\
\text { n zone } \\
\text { in mm) }\end{array}$ & $\begin{array}{c}\% \\
\text { Activity } \\
\text { index }\end{array}$ \\
\hline Hexane & 7 & 29.2 & 10 & 45.4 & 7 & 26.9 \\
\hline $\begin{array}{l}\text { Methylene } \\
\text { chloride }\end{array}$ & 9 & 37.5 & 8 & 36.4 & 12 & 46.1 \\
\hline Butanol & 16 & 66.7 & 14 & 63.6 & 19 & 73.1 \\
\hline Ampicillin & 24 & 100 & 22 & 100 & NA & ---- \\
\hline Colitrimazole & NA & ---- & NA & ---- & 26 & 100 \\
\hline
\end{tabular}

\subsubsection{Antioxidant activity assessment}

The antioxidant activity of hexane, methylene chloride and butanol fractions, was assessed using ABTS method [13]. A control experiment and another one using ascorbic acid as a reference antioxidant material were conducted. Table 2 showed that the butanol subfraction had inhibited (54\%) of the free radicals, followed by methylene chloride fraction (36.8\%). The hexane fraction had inhibited $(17.6 \%)$ of the free radicals, respectively.

The free radicals of 2,2'-azino-bis (3ethylbenzthiazoline-6-sulphonic acid) (ABTS) is used for detection of the antioxidant activity of the plant extracts. Butanol has the highest scavenging activity. The scavenging effect of the extracts and standard on the ABTS radical decreased in the following order: ascorbic acid $>$ butanol fraction $>$ methylene chloride fraction $>$ hexane fraction. (Table 2 and Fig. 1), respectively.
Table 2: The antioxidant activity of the extracts of L. usitatissimum by ABTS method.

\begin{tabular}{|l|l|l|}
\hline Fractions & $\begin{array}{c}\text { Absorbance } \\
\text { of samples }\end{array}$ & $\begin{array}{c}\text { \% } \\
\text { inhibition }\end{array}$ \\
\hline Control of ABTS & 0.505 & $0 \%$ \\
\hline Ascorbic-acid & 0.060 & $88.1 \%$ \\
\hline Hexane & 0.416 & $17.6 \%$ \\
\hline Methylene chloride & 0.319 & $36.8 \%$ \\
\hline Butanol & 0.232 & $54.0 \%$ \\
\hline
\end{tabular}

Fig. 1: The antioxidant activity of the extracts of $L$.

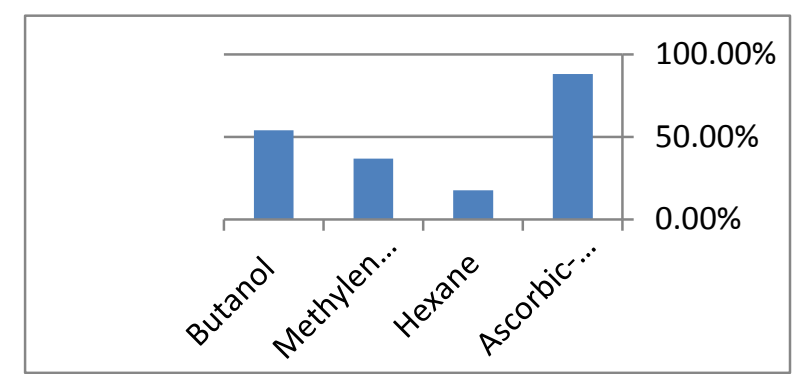

usitatissimum by ABTS method.

\subsubsection{Cytotoxic assessment}

In Egypt, liver cancer is the second cause of deaths from cancer after breast cancer and it is the third frequent occurring cancer after bladder and breast cancer and hepatocellular carcinoma (HCC) is a major health problem [14]. The natural extracts have a vital role on cancer chemoprevention and chemotherapy [15].

The butanol extract and methylene chloride extract were "moderate", hexane extract was "weak" against HepG2 cell line [16].

The results (Table 3 ) indicated that the in vitro cytotoxicity against MCF-7, IC $\mathrm{C}_{50}(\mu \mathrm{g} / \mathrm{ml})$, of the butanol extract was "strong", methylene chloride extract and hexane extract were "weak".

Table 3: Cytotoxic activity assessment of $L$. usitatissimum extracts against human tumor cells HePG2 and MCF-7.

\begin{tabular}{|l|c|c|}
\hline \multirow{2}{*}{ Fractions } & \multicolumn{2}{|c|}{ In vitro Cytotoxicity IC50 $(\mu \mathrm{g} / \mathrm{ml})$} \\
\cline { 2 - 3 } & MCF-7 & HePG2 \\
\hline 5-FU & $4.7 \pm 0.11$ & $6.6 \pm 0.24$ \\
\hline Hexane & $63.0 \pm 3.03$ & $76.7 \pm 2.75$ \\
\hline $\begin{array}{l}\text { Methylene } \\
\text { chloride }\end{array}$ & $55.8 \pm 2.84$ & $47.5 \pm 1.96$ \\
\hline Butanol & $13.5 \pm 0.85$ & $23.2 \pm 1.10$ \\
\hline
\end{tabular}


IC50 ( $\mu \mathrm{g} / \mathrm{ml}): 1$ - 10 (very strong). 11 - 20 (strong). 21 50 (moderate). 51 - 100 (weak) and above 100 (noncytotoxic)

\subsection{Preparation of Lu 3d-loaded pluronic nanoparticles}

The Lu 3d-loaded pluronic nanoparticles were prepared using nanoprecipitation technique through a modified procedure. This preparation technique is appropriate for encapsulation of hydrophobic compounds such as the subfraction Lu $3 d$ obtained in the current study. Also, the encapsulation of these water-insoluble compounds into nano-sized particles enhances their dissolution and consequently improves their bioavailability. It was found that their limited aqueous solubility has been enhanced upon their nanoformulation. Nanoformulation of $\mathrm{Lu} 3 \mathrm{~d}$ has also led to a stable colloidal dispersion with strong green color, indicating their homogenous distribution in the aqueous medium at a significantly higher concentration than that obtained using other solvents.

\subsection{Particle size, zeta potential and surface morphology}

The average diameters of the prepared plain and Lu $3 \mathrm{~d}$-loaded pluronic nanoparticles were found to be $207 \pm 12$ and $225 \pm 18 \mathrm{~nm}$, respectively as determined by DLS (Figure 2). As can also be noted, the particle size of plain nanoparticles is relatively less than that of Lu $3 \mathrm{~d}$-loaded nanoparticles. The charges on the developed plain and Lu 3d-loaded nanoparticles were found negative with the values of -11 and -17 , respectively as determined from the zeta potential measurements (Figure 3 ). The size of the prepared nanoparticles was also estimated from the transmission electron microscopy, TEM (Figure 4). With the aid of TEM particle analysis software (NanoScope Analysis, Veeco Co, USA), the average diameter of these plain and Lu $3 \mathrm{~d}$-loaded pluronic nanoparticles was found to be $18 \pm 2.6 \mathrm{~nm}$ and $48 \pm 2.9 \mathrm{~nm}$, respectively.

The TEM micrographs of plain pluronic nanoparticles and Lu 3d-loaded nanoparticles are illustrated in Figure 4. From the figure, it can be noted that all the developed plain and Lu $3 \mathrm{~d}$ loaded nanoparticles are spherical with almost smooth surfaces.

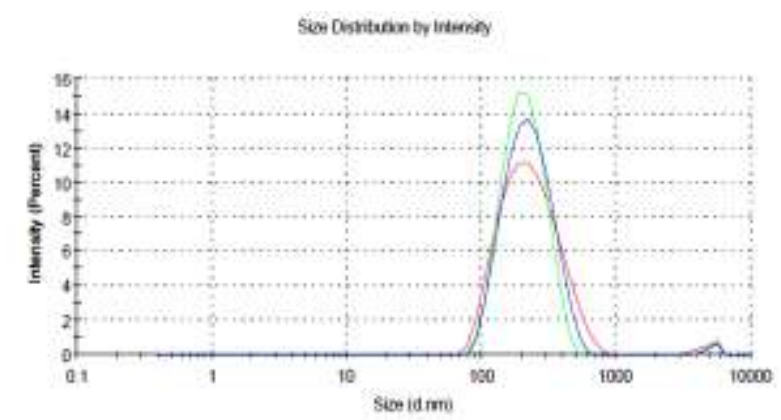

Figure 2. The mean particle size of the developed pluronic nanoparticles.
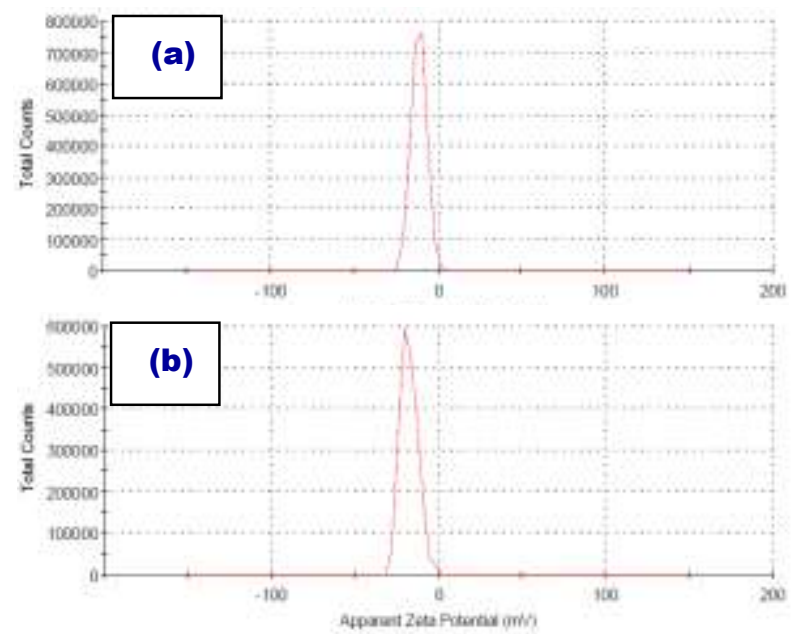

Figure 3. Zeta potential values of (a) plain pluronic nanoparticles, and (b) Lu 3d-loaded pluronic nanoparticles.

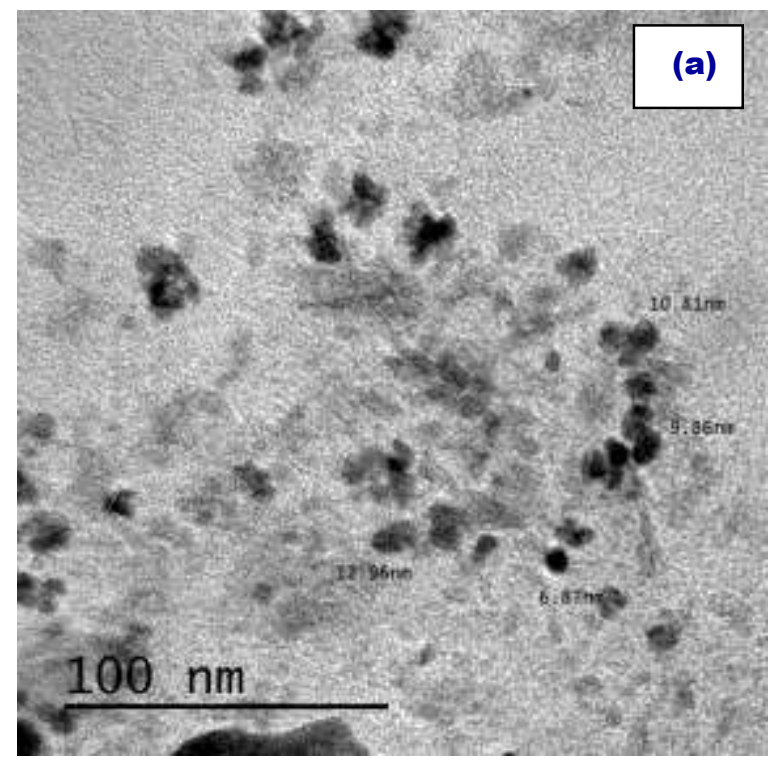




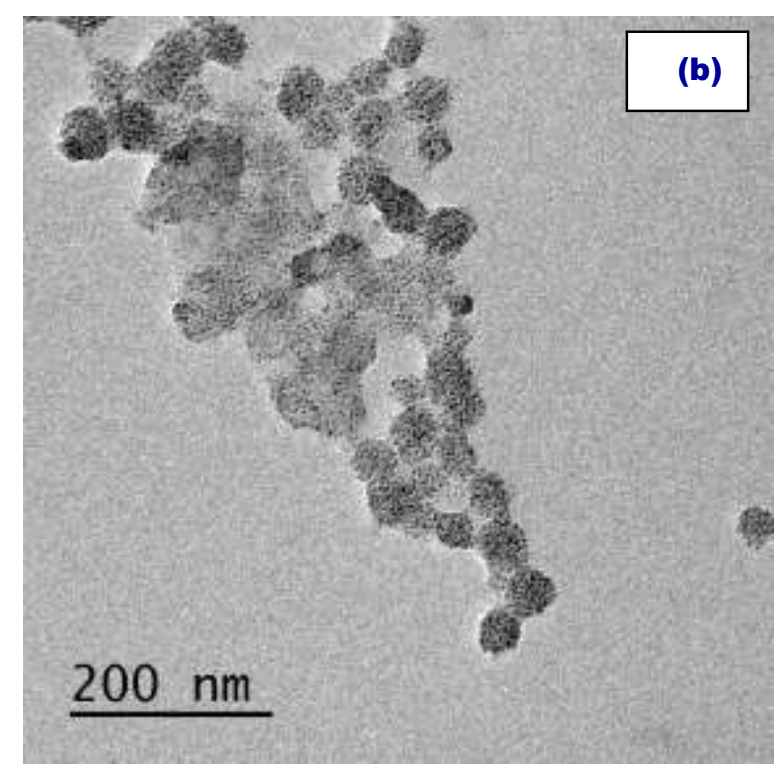

Figure 4. Transmission electron micrographs of (a) plain pluronic nanoparticles, and (b) Lu 3d-loaded pluronic nanoparticles.

\subsection{In-vitro biodegradation study}

An in-vitro biodegradation study of the Lu $3 d$ loaded pluronic nanoparticles was performed in PBS, pH 7.4 in presence of lysozyme. The weight loss percentage of the nanoparticles as a function of time was determined and taken as a measure of degradation. Figure 5 demonstrates the degradation pattern of the developed nanoparticles. As apparent from the figure, the nanoparticles attained higher degradation rates in presence of lysozyme. For instance, the percentage of degraded weights $\left(W_{d} \%\right)$ in presence of the enzyme was almost $89.4 \%$ after 2 days.

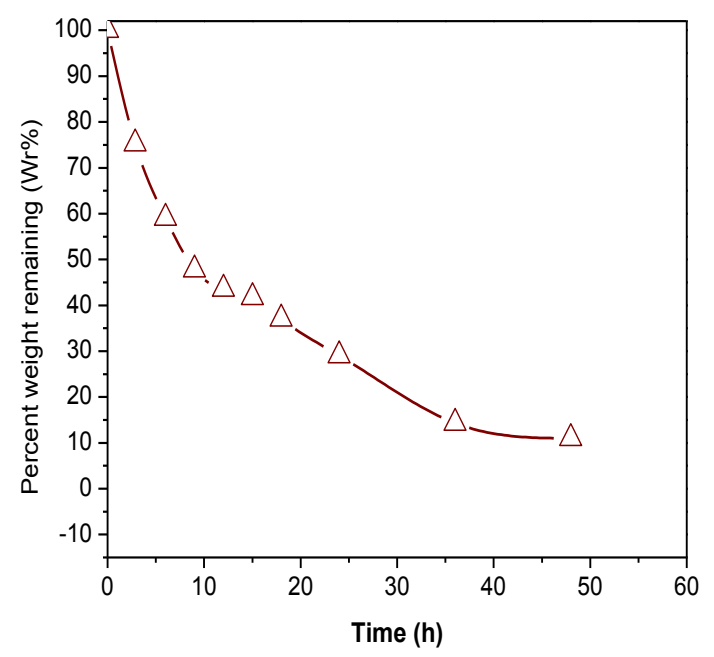

Figure 5. Degradation profile of the developed Lu 3dloaded pluronic nanoparticles at $37^{\circ} \mathrm{C}$ in PBS ( $\left.\mathrm{pH} 7.4\right)$. The values are average of three triplicates.

\subsection{In-vitro cumulative release studies}

The entrapment efficiency (EE\%) of the loaded Lu $3 d$ in the developed pluronic nanoparticles was determined and found to be in the range $88.9 \pm 1$ to $90.2 \pm 2$.

The cumulative release profile of the loaded Lu $3 \mathrm{~d}$ from the pluronic nanoparticles at $37^{\circ} \mathrm{C}$ in PBS of pH 7.4 is shown in Figure 6. As apparent from the figure, the percent of the Lu $3 d$ loaded pluronic nanoparticles released increased gradually with time until attaining almost a constant value after about 36 hours.

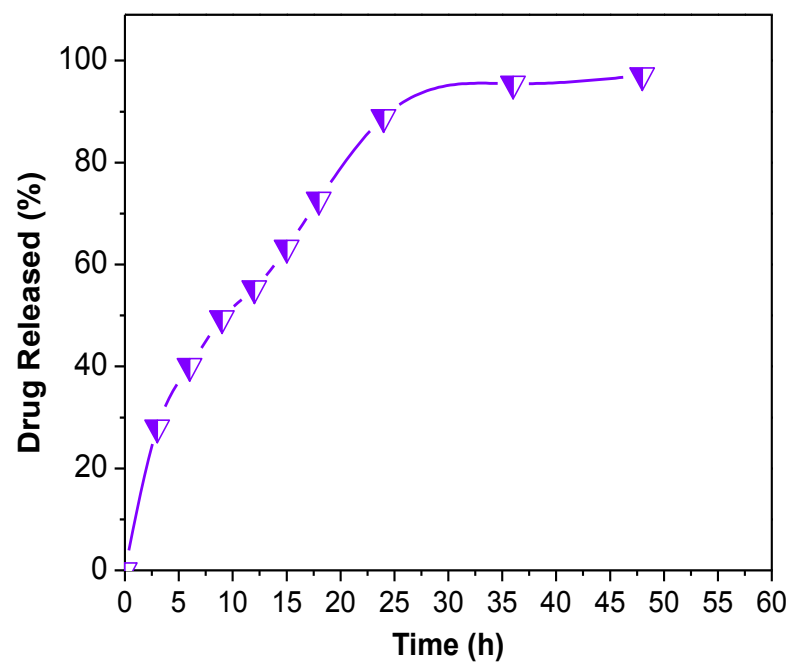

Figure 6. Release study of the loaded Lu 3d from the pluronic nanoparticles at $37^{\circ} \mathrm{C}$ in PBS, $\mathrm{pH}$ 7.4. The values are average of three triplicates. 
Table 4: MS data of compounds identified by GC/MS analyses (m/z [identity] (rel.int. \%))

\begin{tabular}{|c|c|}
\hline Compound Name & MS Data: $\mathrm{m} / \mathrm{z}$ [identity] (rel. abound.\%) \\
\hline dodecane & $\begin{array}{l}170[\mathrm{M}]^{+}(6.66), 127\left[\mathrm{C}_{9} \mathrm{H}_{19}\right]^{+}(3.33), 112\left[\mathrm{C}_{8} \mathrm{H}_{16}\right]^{+}(4), 98\left[\mathrm{C}_{7} \mathrm{H}_{14}\right]^{+}(6.66), 85\left[\mathrm{C}_{6} \mathrm{H}_{13}\right]^{+}(36.66), 71 \\
{\left[\mathrm{C}_{5} \mathrm{H}_{11}\right]^{+}(56.66), 57\left[\mathrm{C}_{4} \mathrm{H}_{9}\right]^{+}(100) .}\end{array}$ \\
\hline tetradecane & $\begin{array}{l}198[\mathrm{M}]^{+}(5), 169\left[\mathrm{C}_{12} \mathrm{H}_{25}\right]^{+}(1.66), 155\left[\mathrm{C}_{11} \mathrm{H}_{23}\right]^{+}(2.66), 141\left[\mathrm{C}_{10} \mathrm{H}_{21}\right]^{+}(3.33), 126\left[\mathrm{C}_{9} \mathrm{H}_{18}\right]^{+} \\
(3.33), 112\left[\mathrm{C}_{8} \mathrm{H}_{16}\right]^{+}(6.66), 99\left[\mathrm{C}_{7} \mathrm{H}_{15}\right]^{+}(10), 85\left[\mathrm{C}_{6} \mathrm{H}_{13}\right]^{+}(46.66), 71\left[\mathrm{C}_{5} \mathrm{H}_{11}\right]^{+}(70), 57\left[\mathrm{C}_{4} \mathrm{H}_{9}\right]^{+}(100) .\end{array}$ \\
\hline hexadecane & $\begin{array}{l}226[\mathrm{M}]^{+}(5.55), 183\left[\mathrm{C}_{13} \mathrm{H}_{27}\right]^{+}(1.11), 169\left[\mathrm{C}_{12} \mathrm{H}_{25}\right]^{+}(3.33), 155\left[\mathrm{C}_{11} \mathrm{H}_{23}\right]^{+}(3.33), 141\left[\mathrm{C}_{10} \mathrm{H}_{21}\right]^{+} \\
(4.44), 127\left[\mathrm{C}_{9} \mathrm{H}_{19}\right]^{+}(6.66), 113\left[\mathrm{C}_{8} \mathrm{H}_{17}\right]^{+}(10), 99\left[\mathrm{C}_{7} \mathrm{H}_{15}\right]^{+}(16.66), 85\left[\mathrm{C}_{6} \mathrm{H}_{13}\right]^{+}(48.88), 71\left[\mathrm{C}_{5} \mathrm{H}_{11}\right]^{+} \\
(68.88), 57\left[\mathrm{C}_{4} \mathrm{H}_{9}\right]^{+}(100) .\end{array}$ \\
\hline heptadecane & $\begin{array}{l}240[\mathrm{M}]^{+}(3.33), 197\left[\mathrm{C}_{14} \mathrm{H}_{29}\right]^{+}(2.22), 183\left[\mathrm{C}_{13} \mathrm{H}_{27}\right]^{+}(2.44), 169\left[\mathrm{C}_{12} \mathrm{H}_{25}\right]^{+}(2.22), 155\left[\mathrm{C}_{11} \mathrm{H}_{23}\right]^{+} \\
(2.22), 141\left[\mathrm{C}_{10} \mathrm{H}_{21}\right]^{+}(4.44), 127\left[\mathrm{C}_{9} \mathrm{H}_{19}\right]^{+}(4.44), 111\left[\mathrm{C}_{8} \mathrm{H}_{15}\right]^{+}(14.44), 97\left[\mathrm{C}_{7} \mathrm{H}_{13}\right]^{+}(67.77), 85 \\
{\left[\mathrm{C}_{6} \mathrm{H}_{13}\right]^{+}(28.88), 71\left[\mathrm{C}_{5} \mathrm{H}_{11}\right]^{+}(44.44), 57\left[\mathrm{C}_{4} \mathrm{H}_{9}\right]^{+}(100) .}\end{array}$ \\
\hline octadecane & $\begin{array}{l}254[\mathrm{M}]^{+}(3.33), 225\left[\mathrm{C}_{16} \mathrm{H}_{33}\right]^{+}(1.11), 211\left[\mathrm{C}_{15} \mathrm{H}_{31}\right]^{+}(1.11), 197\left[\mathrm{C}_{14} \mathrm{H}_{29}\right]^{+}(2.22), 183\left[\mathrm{C}_{13} \mathrm{H}_{27}\right]^{+} \\
(2.44), 169\left[\mathrm{C}_{12} \mathrm{H}_{25}\right]^{+}(3.33), 155\left[\mathrm{C}_{11} \mathrm{H}_{23}\right]^{+}(2.44), 141\left[\mathrm{C}_{10} \mathrm{H}_{21}\right]^{+}(4.44), 127\left[\mathrm{C}_{9} \mathrm{H}_{19}\right]^{+}(6.66), 113 \\
{\left[\mathrm{C}_{8} \mathrm{H}_{17}\right]^{+}(11.11), 99\left[\mathrm{C}_{7} \mathrm{H}_{15}\right]^{+}(18.88), 85\left[\mathrm{C}_{6} \mathrm{H}_{13}\right]^{+}(48.88), 71\left[\mathrm{C}_{5} \mathrm{H}_{11}\right]^{+}(68.88), 57\left[\mathrm{C}_{4} \mathrm{H}_{9}\right]^{+}(100),}\end{array}$ \\
\hline eicosane & $\begin{array}{l}282\left[\mathrm{MM}^{+}(3.33), 241\left[\mathrm{C}_{17} \mathrm{H}_{37}\right](3), 224\left[\mathrm{C}_{16} \mathrm{H}_{32}\right]^{+}(3.33), 211\left[\mathrm{C}_{15} \mathrm{H}_{31}\right]^{+}(3.33), 197\left[\mathrm{C}_{14} \mathrm{H}_{29}\right]^{+}(3.33),\right. \\
183\left[\mathrm{C}_{13} \mathrm{H}_{27}\right]^{+}(3.33), 169\left[\mathrm{C}_{12} \mathrm{H}_{25}\right]^{+}(3.66), 141\left[\mathrm{C}_{10} \mathrm{H}_{21}\right]^{+}(6.66), 127\left[\mathrm{C}_{9} \mathrm{H}_{19}\right]^{+}(10), 113\left[\mathrm{C}_{8} \mathrm{H}_{17}\right]^{+} \\
(13.33), 99\left[\mathrm{C}_{7} \mathrm{H}_{15}\right]^{+}(21.66), 85\left[\mathrm{C}_{6} \mathrm{H}_{13}\right]^{+}(60), 71\left[\mathrm{C}_{5} \mathrm{H}_{11}\right]^{+}(75), 57\left[\mathrm{C}_{4} \mathrm{H}_{9}\right]^{+}(100) .\end{array}$ \\
\hline heneicosane & $\begin{array}{l}296[\mathrm{M}]^{+}(7.69), 281\left[\mathrm{C}_{20} \mathrm{H}_{41}\right]^{+}(2.20), 267\left[\mathrm{C}_{19} \mathrm{H}_{39}\right]^{+}(1.98), 253\left[\mathrm{C}_{18} \mathrm{H}_{37}\right]^{+}(2.20), 239\left[\mathrm{C}_{17} \mathrm{H}_{35}\right]^{+} \\
(4.40), 225\left[\mathrm{C}_{16} \mathrm{H}_{33}\right]^{+}(4.40), 211\left[\mathrm{C}_{15} \mathrm{H}_{31}\right]^{+}(3.30), 197\left[\mathrm{C}_{14} \mathrm{H}_{29}\right]^{+}(5.49), 183\left[\mathrm{C}_{13} \mathrm{H}_{27}\right]^{+}(6.59), 169 \\
{\left[\mathrm{C}_{12} \mathrm{H}_{25}\right]^{+}(6.59), 155\left[\mathrm{C}_{11} \mathrm{H}_{23}\right]^{+}(9.01), 141\left[\mathrm{C}_{10} \mathrm{H}_{21}\right]^{+}(9.89), 125\left[\mathrm{C}_{9} \mathrm{H}_{17}\right]^{+}(17.58), 111\left[\mathrm{C}_{8} \mathrm{H}_{15}\right]^{+}} \\
(29.67), 97\left[\mathrm{C}_{7} \mathrm{H}_{13}\right]^{+}(46.15), 85\left[\mathrm{C}_{6} \mathrm{H}_{13}\right]^{+}(59.34), 71\left[\mathrm{C}_{5} \mathrm{H}_{11}\right]^{+}(74.95), 57\left[\mathrm{C}_{4} \mathrm{H}_{9}\right]^{+}(100) .\end{array}$ \\
\hline docosane & $\begin{array}{l}310[\mathrm{M}]^{+}(10.99), 281\left[\mathrm{C}_{20} \mathrm{H}_{41}\right]^{+}(2.20), 267\left[\mathrm{C}_{19} \mathrm{H}_{39}\right]^{+}(2.42), 253\left[\mathrm{C}_{18} \mathrm{H}_{37}\right]^{+}(3.30), 239\left[\mathrm{C}_{17} \mathrm{H}_{35}\right]^{+} \\
(2.42), 225\left[\mathrm{C}_{16} \mathrm{H}_{33}\right]^{+}(4.40), 211\left[\mathrm{C}_{15} \mathrm{H}_{31}\right]^{+}(4.40), 197\left[\mathrm{C}_{14} \mathrm{H}_{29}\right]^{+}(4.40), 183\left[\mathrm{C}_{13} \mathrm{H}_{27}\right]^{+}(6.59), 169 \\
{\left[\mathrm{C}_{12} \mathrm{H}_{25}\right]^{+}(6.59), 155\left[\mathrm{C}_{11} \mathrm{H}_{23}\right]^{+}(8.79), 141\left[\mathrm{C}_{10} \mathrm{H}_{21}\right]^{+}(10.99), 125\left[\mathrm{C}_{9} \mathrm{H}_{17}\right]^{+}(13.19), 111\left[\mathrm{C}_{8} \mathrm{H}_{15}\right]^{+}} \\
(22.20), 97\left[\mathrm{C}_{7} \mathrm{H}_{13}\right]^{+}(28.79), 85\left[\mathrm{C}_{6} \mathrm{H}_{13}\right]^{+}(61.54), 71\left[\mathrm{C}_{5} \mathrm{H}_{11}\right]^{+}(80.22), 57\left[\mathrm{C}_{4} \mathrm{H}_{9}\right]^{+}(100) .\end{array}$ \\
\hline tricosane & $\begin{array}{l}324[\mathrm{M}]^{+}(8.79), 295\left[\mathrm{C}_{21} \mathrm{H}_{43}\right]^{+}(2.20), 281\left[\mathrm{C}_{20} \mathrm{H}_{41}\right]^{+}(4.18), 267\left[\mathrm{C}_{19} \mathrm{H}_{39}\right]^{+}(3.30), 253\left[\mathrm{C}_{18} \mathrm{H}_{37}\right]^{+} \\
(3.30), 239\left[\mathrm{C}_{17} \mathrm{H}_{35}\right]^{+}(3.30), 225\left[\mathrm{C}_{16} \mathrm{H}_{33}\right]^{+}(4.62), 211\left[\mathrm{C}_{15} \mathrm{H}_{31}\right]^{+}(4.84), 197\left[\mathrm{C}_{14} \mathrm{H}_{29}\right]^{+}(5.49), 183 \\
{\left[\mathrm{C}_{13} \mathrm{H}_{27}\right]^{+}(6.59), 169\left[\mathrm{C}_{12} \mathrm{H}_{25}\right]^{+}(6.59), 155\left[\mathrm{C}_{11} \mathrm{H}_{23}\right]^{+}(10.77), 141\left[\mathrm{C}_{10} \mathrm{H}_{21}\right]^{+}(9.89), 125\left[\mathrm{C}_{9} \mathrm{H}_{17}\right]^{+}} \\
(17.58), 111\left[\mathrm{C}_{8} \mathrm{H}_{15}\right]^{+}(29.67), 97\left[\mathrm{C}_{7} \mathrm{H}_{13}\right]^{+}(44.18), 85\left[\mathrm{C}_{6} \mathrm{H}_{13}\right]^{+}(62.64), 71\left[\mathrm{C}_{5} \mathrm{H}_{11}\right]^{+}(81.10), 57 \\
{\left[\mathrm{C}_{4} \mathrm{H}_{9}\right]^{+}(100) .}\end{array}$ \\
\hline tetracosane & $\begin{array}{l}338[\mathrm{M}]^{+}(1.11), 310\left[\mathrm{C}_{22} \mathrm{H}_{46}\right](2.22), 281\left[\mathrm{C}_{20} \mathrm{H}_{41}\right]^{+}(2.22), 267\left[\mathrm{C}_{19} \mathrm{H}_{39}\right]^{+}(2.22), 253\left[\mathrm{C}_{18} \mathrm{H}_{37}\right]^{+} \\
(1.11), 239\left[\mathrm{C}_{17} \mathrm{H}_{35}\right]^{+}(2), 225\left[\mathrm{C}_{16} \mathrm{H}_{33}\right]^{+}(2.22), \quad 211\left[\mathrm{C}_{15} \mathrm{H}_{31}\right]^{+}(2.22), 197\left[\mathrm{C}_{14} \mathrm{H}_{29}\right]^{+}(2.22), 183 \\
{\left[\mathrm{C}_{13} \mathrm{H}_{27}\right]^{+}(3.33), 169\left[\mathrm{C}_{12} \mathrm{H}_{25}\right]^{+}(2.44), 155\left[\mathrm{C}_{11} \mathrm{H}_{23}\right]^{+}(5.55), 141\left[\mathrm{C}_{10} \mathrm{H}_{21}\right]^{+}(7.77), 127\left[\mathrm{C}_{9} \mathrm{H}_{19}\right]^{+}} \\
(8.88), 113\left[\mathrm{C}_{8} \mathrm{H}_{17}\right]^{+}(13.33), 99\left[\mathrm{C}_{7} \mathrm{H}_{15}\right]^{+}(20), 85\left[\mathrm{C}_{6} \mathrm{H}_{13}\right]^{+}(48.88), 71\left[\mathrm{C}_{5} \mathrm{H}_{11}\right]^{+}(71.11), 57\left[\mathrm{C}_{4} \mathrm{H}_{9}\right]^{+} \\
(100) .\end{array}$ \\
\hline pentacosane & $\begin{array}{l}352[\mathrm{M}]^{+}(2.22), 337\left[\mathrm{C}_{24} \mathrm{H}_{49}\right]^{+}(1.11), 295\left[\mathrm{C}_{21} \mathrm{H}_{43}\right]^{+}(0.66), 281\left[\mathrm{C}_{20} \mathrm{H}_{41}\right]^{+}(6.44), 267\left[\mathrm{C}_{19} \mathrm{H}_{39}\right]^{+} \\
(3.33), 253\left[\mathrm{C}_{18} \mathrm{H}_{37}\right]^{+}(3.33), 239\left[\mathrm{C}_{17} \mathrm{H}_{35}\right]^{+}(2.22), 225\left[\mathrm{C}_{16} \mathrm{H}_{33}\right]^{+}(2.22), 211\left[\mathrm{C}_{15} \mathrm{H}_{31}\right]^{+}(2.22), 197 \\
{\left[\mathrm{C}_{14} \mathrm{H}_{29}\right]^{+}(4.44), 183\left[\mathrm{C}_{13} \mathrm{H}_{27}\right]^{+}(3.33), 169 \mathrm{n}\left[\mathrm{C}_{12} \mathrm{H}_{25}\right]^{+}(4.44), 155\left[\mathrm{C}_{11} \mathrm{H}_{23}\right]^{+}(6.44), 141\left[\mathrm{C}_{10} \mathrm{H}_{21}\right]^{+}} \\
(8.88), 129\left[\mathrm{C}_{9} \mathrm{H}_{21}\right]^{+}(13.55), 111\left[\mathrm{C}_{8} \mathrm{H}_{15}\right]^{+}(17.55), 97\left[\mathrm{C}_{7} \mathrm{H}_{13}\right]^{+}(26.66), 85\left[\mathrm{C}_{6} \mathrm{H}_{13}\right]^{+}(54.44), 71 \\
{\left[\mathrm{C}_{5} \mathrm{H}_{11}\right]^{+}(73.33), 57\left[\mathrm{C}_{4} \mathrm{H}_{9}\right]^{+}(100) .}\end{array}$ \\
\hline hexacosane & $\begin{array}{l}366[\mathrm{M}]^{+}(2.44), 309\left[\mathrm{C}_{22} \mathrm{H}_{45}\right]^{+}(1.11), 295\left[\mathrm{C}_{21} \mathrm{H}_{43}\right]^{+}(1.11), 281\left[\mathrm{C}_{20} \mathrm{H}_{41}\right]^{+}(5.55), 267\left[\mathrm{C}_{19} \mathrm{H}_{39}\right]^{+}(3.33), 25 \\
3\left[\mathrm{C}_{18} \mathrm{H}_{37}\right]^{+}(3.33), 239\left[\mathrm{C}_{17} \mathrm{H}_{35}\right]^{+}(2.22), 225\left[\mathrm{C}_{16} \mathrm{H}_{33}\right]^{+}(2), 211\left[\mathrm{C}_{15} \mathrm{H}_{31}\right]^{+}(2.44), 197\left[\mathrm{C}_{14} \mathrm{H}_{29}\right]^{+}(3.33), 183[ \\
\left.\mathrm{C}_{13} \mathrm{H}_{27}\right]^{+}(3.33), 169\left[\mathrm{C}_{12} \mathrm{H}_{25}\right]^{+}(4.44), 155\left[\mathrm{C}_{11} \mathrm{H}_{23}\right]^{+}(6.66), 141\left[\mathrm{C}_{10} \mathrm{H}_{21}\right]^{+}(7.77), 129\left[\mathrm{C}_{9} \mathrm{H}_{21}\right]^{+}(10), 113\left[\mathrm{C}_{8}\right. \\
\left.\mathrm{H}_{17}\right]^{+}(13.33), 97\left[\mathrm{C}_{7} \mathrm{H}_{13}\right]^{+}(21.11), 85\left[\mathrm{C}_{6} \mathrm{H}_{13}\right]^{+}(48.88), 71\left[\mathrm{C}_{5} \mathrm{H}_{11}\right]^{+}(62.22), 57\left[\mathrm{C}_{4} \mathrm{H}_{9}\right]^{+}(100),\end{array}$ \\
\hline heptacosane & $\begin{array}{l}380[\mathrm{M}]^{+}(2.22), 337\left[\mathrm{C}_{24} \mathrm{H}_{49}\right]^{+}(1.11), 309\left[\mathrm{C}_{22} \mathrm{H}_{45}\right]^{+}(1.11), 295\left[\mathrm{C}_{21} \mathrm{H}_{43}\right]^{+}(2), 281\left[\mathrm{C}_{20} \mathrm{H}_{41}\right]^{+}(8.88), \\
267\left[\mathrm{C}_{19} \mathrm{H}_{39}\right]^{+}(4.44), 253\left[\mathrm{C}_{18} \mathrm{H}_{37}\right]^{+}(4.44), 239\left[\mathrm{C}_{17} \mathrm{H}_{35}\right]^{+}(2.22), 225\left[\mathrm{C}_{16} \mathrm{H}_{33}\right]^{+}(2.66), 211\left[\mathrm{C}_{15} \mathrm{H}_{31}\right]^{+} \\
(2.66), 197\left[\mathrm{C}_{14} \mathrm{H}_{29}\right]^{+}(4.44), 183\left[\mathrm{C}_{13} \mathrm{H}_{27}\right]^{+}(2.66), 169\left[\mathrm{C}_{12} \mathrm{H}_{25}\right]^{+}(6.66), 155\left[\mathrm{C}_{11} \mathrm{H}_{23}\right]^{+}(7.77), 141 \\
{\left[\mathrm{C}_{10} \mathrm{H}_{21}\right]^{+}(8.88), 129\left[\mathrm{C}_{9} \mathrm{H}_{21}\right]^{+}(14.44), 113\left[\mathrm{C}_{8} \mathrm{H}_{17}\right]^{+}(15.55), 97\left[\mathrm{C}_{7} \mathrm{H}_{13}\right]^{+}(27.77), 85\left[\mathrm{C}_{6} \mathrm{H}_{13}\right]^{+}} \\
(54.44), 71\left[\mathrm{C}_{5} \mathrm{H}_{11}\right]^{+}(75.55), 57\left[\mathrm{C}_{4} \mathrm{H}_{9}\right]^{+}(100) .\end{array}$ \\
\hline
\end{tabular}




\begin{tabular}{|c|c|}
\hline octacosane & $\begin{array}{l}394[\mathrm{M}]^{+}(1.66), 337\left[\mathrm{C}_{24} \mathrm{H}_{49}\right]^{+}(0.66), 323\left[\mathrm{C}_{23} \mathrm{H}_{47}\right]^{+}(0.66), 309\left[\mathrm{C}_{22} \mathrm{H}_{45}\right]^{+}(1.66), 295\left[\mathrm{C}_{21} \mathrm{H}_{43}\right]^{+} \\
(1.66), 281\left[\mathrm{C}_{20} \mathrm{H}_{41}\right]^{+}(3.66), 267\left[\mathrm{C}_{19} \mathrm{H}_{39}\right]^{+}(3), 253\left[\mathrm{C}_{18} \mathrm{H}_{37}\right]^{+}(3), 239\left[\mathrm{C}_{17} \mathrm{H}_{35}\right]^{+}(3.33), 225 \\
{\left[\mathrm{C}_{16} \mathrm{H}_{33}\right]^{+}(1.66), 211\left[\mathrm{C}_{15} \mathrm{H}_{31}\right]^{+}(3.33), 197\left[\mathrm{C}_{14} \mathrm{H}_{29}\right]^{+}(3.33), 183\left[\mathrm{C}_{13} \mathrm{H}_{27}\right]^{+}(3.33), 169\left[\mathrm{C}_{12} \mathrm{H}_{25}\right]^{+}} \\
(3.33), 141\left[\mathrm{C}_{10} \mathrm{H}_{21}\right]^{+}(6.66), 127\left[\mathrm{C}_{9} \mathrm{H}_{19}\right]^{+}(10), 113\left[\mathrm{C}_{8} \mathrm{H}_{17}\right]^{+}(13.33), 99\left[\mathrm{C}_{7} \mathrm{H}_{15}\right]^{+}(20), 85\left[\mathrm{C}_{6} \mathrm{H}_{13}\right]^{+} \\
(56.66), 71\left[\mathrm{C}_{5} \mathrm{H}_{11}\right]^{+}(76.66), 57\left[\mathrm{C}_{4} \mathrm{H}_{9}\right]^{+}(100) .\end{array}$ \\
\hline nonacosane & $\begin{array}{l}408[\mathrm{M}]^{+}(1.66), 379\left[\mathrm{C}_{27} \mathrm{H}_{55}\right]^{+}(0.33), 351\left[\mathrm{C}_{25} \mathrm{H}_{51}\right]^{+}(0.33), 309\left[\mathrm{C}_{22} \mathrm{H}_{45}\right]^{+}(0.33), 365\left[\mathrm{C}_{26} \mathrm{H}_{53}\right]^{+} \\
(0.33), 323\left[\mathrm{C}_{23} \mathrm{H}_{47}\right]^{+}(0.66), 295\left[\mathrm{C}_{21} \mathrm{H}_{43}\right]^{+}(1.66), 281\left[\mathrm{C}_{20} \mathrm{H}_{41}\right]^{+}(5), 267\left[\mathrm{C}_{19} \mathrm{H}_{39}\right]^{+}(1.33), 253 \\
{\left[\mathrm{C}_{18} \mathrm{H}_{37}\right]^{+}(3), 239\left[\mathrm{C}_{17} \mathrm{H}_{35}\right]^{+}(1.66), 225\left[\mathrm{C}_{16} \mathrm{H}_{33}\right]^{+}(2.66), 183\left[\mathrm{C}_{13} \mathrm{H}_{27}\right]^{+}(3.33), 169\left[\mathrm{C}_{12} \mathrm{H}_{25}\right]^{+}(3.33),} \\
155\left[\mathrm{C}_{11} \mathrm{H}_{23}\right]^{+}(5), 141\left[\mathrm{C}_{10} \mathrm{H}_{21}\right]^{+}(8.33), 127\left[\mathrm{C}_{9} \mathrm{H}_{19}\right]^{+}(10), 113\left[\mathrm{C}_{8} \mathrm{H}_{17}\right]^{+}(13.33), 99\left[\mathrm{C}_{7} \mathrm{H}_{15}\right]^{+}(20), \\
85\left[\mathrm{C}_{6} \mathrm{H}_{13}\right]^{+}(56.66), 71\left[\mathrm{C}_{5} \mathrm{H}_{11}\right]^{+}(76.66), 57\left[\mathrm{C}_{4} \mathrm{H}_{9}\right]^{+}(100) .\end{array}$ \\
\hline triacontane & $\begin{array}{l}422[\mathrm{M}]^{+}(1.66), 365\left[\mathrm{C}_{26} \mathrm{H}_{53}\right]^{+}(0.33), 323\left[\mathrm{C}_{23} \mathrm{H}_{47}\right]^{+}(0.66), 309\left[\mathrm{C}_{22} \mathrm{H}_{45}\right]^{+}(1.66), 295\left[\mathrm{C}_{21} \mathrm{H}_{43}\right]^{+} \\
(1.66), 281\left[\mathrm{C}_{20} \mathrm{H}_{41}\right]^{+}(6.66), 267\left[\mathrm{C}_{19} \mathrm{H}_{39}\right]^{+}(1.33), 253\left[\mathrm{C}_{18} \mathrm{H}_{37}\right]^{+}(3.33), 239\left[\mathrm{C}_{17} \mathrm{H}_{35}\right]^{+}(3.33), 225 \\
{\left[\mathrm{C}_{16} \mathrm{H}_{33}\right]^{+}(1.66), 211\left[\mathrm{C}_{15} \mathrm{H}_{31}\right]^{+}(3), 197\left[\mathrm{C}_{14} \mathrm{H}_{29}\right]^{+}(3.33), 183\left[\mathrm{C}_{13} \mathrm{H}_{27}\right]^{+}(3.33), 169\left[\mathrm{C}_{12} \mathrm{H}_{25}\right]^{+}(3.66),} \\
155\left[\mathrm{C}_{11} \mathrm{H}_{23}\right]^{+}(5), 141\left[\mathrm{C}_{10} \mathrm{H}_{21}\right]^{+}(6.66), 127\left[\mathrm{C}_{9} \mathrm{H}_{19}\right]^{+}(10), 113\left[\mathrm{C}_{8} \mathrm{H}_{17}\right]^{+}(11.66), 99\left[\mathrm{C}_{7} \mathrm{H}_{15}\right]^{+}(20), \\
85\left[\mathrm{C}_{6} \mathrm{H}_{13}\right]^{+}(55), 71\left[\mathrm{C}_{5} \mathrm{H}_{11}\right]^{+}(76.66), 57\left[\mathrm{C}_{4} \mathrm{H}_{9}\right]^{+}(100) .\end{array}$ \\
\hline hentriacontane & $\begin{array}{l}436[\mathrm{M}]^{+}(1.11), 405\left[\mathrm{C}_{29} \mathrm{H}_{57}\right]^{+}(4.44), 295\left[\mathrm{C}_{21} \mathrm{H}_{43}\right]^{+}(2), 281\left[\mathrm{C}_{20} \mathrm{H}_{41}\right]^{+}(27.78), 267\left[\mathrm{C}_{19} \mathrm{H}_{39}\right]^{+} \\
(11.11), 253\left[\mathrm{C}_{18} \mathrm{H}_{37}\right]^{+}(13.56), 97\left[\mathrm{C}_{7} \mathrm{H}_{13}\right]^{+}(22.67), 85\left[\mathrm{C}_{6} \mathrm{H}_{13}\right]^{+}(31.11), 73\left[\mathrm{C}_{5} \mathrm{H}_{13}\right]^{+}(100), 57 \\
{\left[\mathrm{C}_{4} \mathrm{H}_{9}\right]^{+}(66.67) .}\end{array}$ \\
\hline dotriacontane & $\begin{array}{l}450[\mathrm{M}]^{+}(4.62), 405(8.79), 379(3.30), 355(15.60), 337\left[\mathrm{C}_{24} \mathrm{H}_{49}\right]^{+}(3.30), 327(15.38), 323 \\
{\left[\mathrm{C}_{23} \mathrm{H}_{47}\right]^{+}(2.20), 309\left[\mathrm{C}_{22} \mathrm{H}_{45}\right]^{+}(2.20), 295\left[\mathrm{C}_{21} \mathrm{H}_{43}\right]^{+}(4.40), 281\left[\mathrm{C}_{20} \mathrm{H}_{41}\right]^{+}(50.55), 267\left[\mathrm{C}_{19} \mathrm{H}_{39}\right]^{+}} \\
(18.68), 253\left[\mathrm{C}_{18} \mathrm{H}_{37}\right]^{+}(27.47), 239\left[\mathrm{C}_{17} \mathrm{H}_{35}\right]^{+}(8.79), 225\left[\mathrm{C}_{16} \mathrm{H}_{33}\right]^{+}(4.40), 211\left[\mathrm{C}_{15} \mathrm{H}_{31}\right]^{+}(6.81), \\
197\left[\mathrm{C}_{14} \mathrm{H}_{29}\right]^{+}(10.99), 183\left[\mathrm{C}_{13} \mathrm{H}_{27}\right]^{+}(10.99), 169\left[\mathrm{C}_{12} \mathrm{H}_{25}\right]^{+}(6.81), 155\left[\mathrm{C}_{11} \mathrm{H}_{23}\right]^{+}(10.99), 141 \\
{\left[\mathrm{C}_{10} \mathrm{H}_{21}\right]^{+}(13.19), 135(30.77), 127\left[\mathrm{C}_{9} \mathrm{H}_{19}\right]^{+}(15.38), 111\left[\mathrm{C}_{8} \mathrm{H}_{15}\right]^{+}(26.37), 97\left[\mathrm{C}_{7} \mathrm{H}_{13}\right]^{+}(46.15),} \\
85\left[\mathrm{C}_{6} \mathrm{H}_{13}\right]^{+}(60.44), 71\left[\mathrm{C}_{5} \mathrm{H}_{11}\right]^{+}(82.42), 57\left[\mathrm{C}_{4} \mathrm{H}_{9}\right]^{+}(100) .\end{array}$ \\
\hline 2- methyleicosane & $\begin{array}{l}296[\mathrm{M}]^{+}(10.99), 281\left[\mathrm{C}_{20} \mathrm{H}_{41}\right]^{+}(20.88), 267\left[\mathrm{C}_{19} \mathrm{H}_{39}\right]^{+}(6.59), 253\left[\mathrm{C}_{18} \mathrm{H}_{37}\right]^{+}(6.37), 239\left[_{17} \mathrm{H}_{35}\right]^{+} \\
(5.49), 225\left[\mathrm{C}_{16} \mathrm{H}_{33}\right]^{+}(4.62), 211\left[\mathrm{C}_{15} \mathrm{H}_{31}\right]^{+}(4.40), 197\left[\mathrm{C}_{14} \mathrm{H}_{29}\right]^{+}(6.59), 183\left[\mathrm{C}_{13} \mathrm{H}_{27}\right]^{+}(7.69), 169 \\
{\left[\mathrm{C}_{12} \mathrm{H}_{25}\right]^{+}(12.09), 155\left[\mathrm{C}_{11} \mathrm{H}_{23}\right]^{+}(11.21), 141\left[\mathrm{C}_{10} \mathrm{H}_{21}\right]^{+}(13.19), 125\left[\mathrm{C}_{9} \mathrm{H}_{17}\right]^{+}(23.08), 111\left[\mathrm{C}_{8} \mathrm{H}_{15}\right]^{+}} \\
(39.56), 97\left[\mathrm{C}_{7} \mathrm{H}_{13}\right]^{+}(51.65), 83\left[\mathrm{C}_{6} \mathrm{H}_{11}\right]^{+}(79.12), 71\left[\mathrm{C}_{5} \mathrm{H}_{11}\right]^{+}(68.13), 57\left[\mathrm{C}_{4} \mathrm{H}_{9}\right]^{+}(100) .\end{array}$ \\
\hline cetene & $\begin{array}{l}224[\mathrm{M}]^{+}(2.44), 196\left[\mathrm{C}_{14} \mathrm{H}_{28}\right]^{+}(2.22), 181\left[\mathrm{C}_{13} \mathrm{H}_{25}\right]^{+}(1.11), 168\left[\mathrm{C}_{12} \mathrm{H}_{24}\right](2), 153\left[\mathrm{C}_{11} \mathrm{H}_{21}\right]^{+}(2.44), \\
139\left[\mathrm{C}_{10} \mathrm{H}_{19}\right]^{+}(4.66), 125\left[\mathrm{C}_{9} \mathrm{H}_{17}\right]^{+}(15.55), 111\left[\mathrm{C}_{8} \mathrm{H}_{15}\right]^{+}(35.55), 97\left[\mathrm{C}_{7} \mathrm{H}_{13}\right]^{+}(77.77), 83\left[\mathrm{C}_{6} \mathrm{H}_{11}\right]^{+} \\
(86.66), 69\left[\mathrm{C}_{5} \mathrm{H}_{9}\right]^{+}(84.44), 55\left[\mathrm{C}_{4} \mathrm{H}_{7}\right]^{+}(100) .\end{array}$ \\
\hline 1-octadecene & $\begin{array}{l}252[\mathrm{M}]^{+}(2.22), 224\left[\mathrm{C}_{16} \mathrm{H}_{32}\right](1.11), 195\left[\mathrm{C}_{14} \mathrm{H}_{27}\right]^{+}(0.44), 181\left[\mathrm{C}_{13} \mathrm{H}_{25}\right]^{+}(2), 167\left[\mathrm{C}_{12} \mathrm{H}_{23}\right]^{+}(2.22), \\
153\left[\mathrm{C}_{11} \mathrm{H}_{21}\right]^{+}(4.44), 139\left[\mathrm{C}_{10} \mathrm{H}_{19}\right]^{+}(6.88), 125\left[\mathrm{C}_{9} \mathrm{H}_{17}\right]^{+}(17.77), 111\left[\mathrm{C}_{8} \mathrm{H}_{15}\right]^{+}(42.22), 97\left[\mathrm{C}_{7} \mathrm{H}_{13}\right]^{+} \\
(82.11), 83\left[\mathrm{C}_{6} \mathrm{H}_{11}\right]^{+}(94.44), 69\left[\mathrm{C}_{5} \mathrm{H}_{9}\right]^{+}(78), 55\left[\mathrm{C}_{4} \mathrm{H}_{7}\right]^{+}(100) .\end{array}$ \\
\hline 2,4-heptadienal & $110[\mathrm{M}]^{+}(21.66), 95\left[\mathrm{C}_{6} \mathrm{H}_{7} \mathrm{O}\right]^{+}(5), 81\left[\mathrm{C}_{5} \mathrm{H}_{5} \mathrm{O}\right]^{+}(100), 67(13.33), 53\left[\mathrm{C}_{3} \mathrm{HO}^{+}(18.33)\right.$ \\
\hline 2-decenal & $\begin{array}{l}154[\mathrm{M}]^{+}(0.67), 110\left[\mathrm{C}_{7} \mathrm{H}_{10} \mathrm{O}\right]^{+}(16.67), 98\left[\mathrm{C}_{6} \mathrm{H}_{10} \mathrm{O}\right]^{+}(30), 83\left[\mathrm{C}_{5} \mathrm{H}_{7} \mathrm{O}\right]^{+}(66.67), 70\left[\mathrm{C}_{4} \mathrm{H}_{6} \mathrm{O}\right]^{+}(100), \\
55\left[\mathrm{C}_{3} \mathrm{H}_{3} \mathrm{O}\right]^{+}(86.67) .\end{array}$ \\
\hline 9,17-octadecadienal & 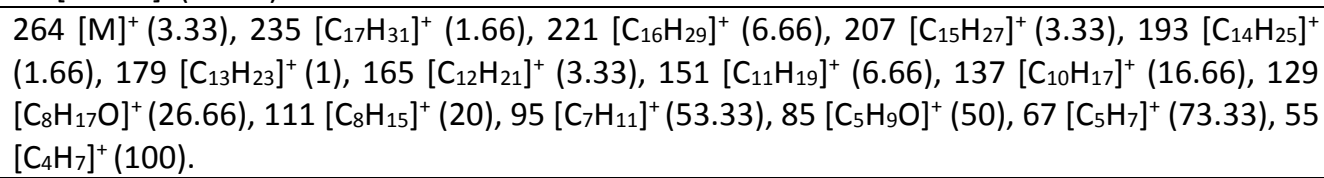 \\
\hline $\begin{array}{l}\text { 9,12,15-octadecatrien- } \\
1 \text {-ol }\end{array}$ & 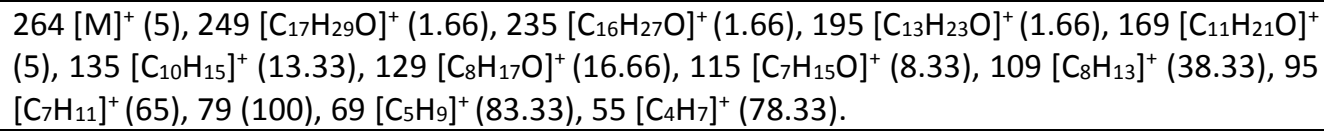 \\
\hline pentadecanoic acid & $\begin{array}{l}242[\mathrm{M}]^{+}(48.33), 227\left[\mathrm{C}_{14} \mathrm{H}_{27} \mathrm{O}_{2}\right]^{+}(3.33), 213\left[\mathrm{C}_{13} \mathrm{H}_{25} \mathrm{O}_{2}\right]^{+}(20), 199\left[\mathrm{C}_{12} \mathrm{H}_{23} \mathrm{O}_{2}\right]^{+}(30), 185 \\
{\left[\mathrm{C}_{11} \mathrm{H}_{21} \mathrm{O}_{2}\right]^{+}(21.66), 171\left[\mathrm{C}_{10} \mathrm{H}_{19} \mathrm{O}_{2}\right]^{+}(15), 157\left[\mathrm{C}_{9} \mathrm{H}_{17} \mathrm{O}_{2}\right]^{+}(13.33), 143\left[\mathrm{C}_{8} \mathrm{H}_{15} \mathrm{O}_{2}\right]^{+}(23.33), 129} \\
{\left[\mathrm{C}_{7} \mathrm{H}_{13} \mathrm{O}_{2}\right]^{+}(50), 115\left[\mathrm{C}_{6} \mathrm{H}_{11} \mathrm{O}_{2}\right]^{+}(20), 101\left[\mathrm{C}_{5} \mathrm{H}_{9} \mathrm{O}_{2}\right]^{+}(10), 87\left[\mathrm{C}_{4} \mathrm{H}_{7} \mathrm{O}_{2}\right]^{+}(21.66), 73\left[\mathrm{C}_{3} \mathrm{H}_{5} \mathrm{O}_{2}\right]^{+}(100),} \\
60\left[\mathrm{C}_{2} \mathrm{H}_{4} \mathrm{O}_{2}\right](73.33) .\end{array}$ \\
\hline hexadecanoic acid & $\begin{array}{l}256[\mathrm{M}]^{+}(81.66), 227\left[\mathrm{C}_{14} \mathrm{H}_{27} \mathrm{O}_{2}\right]^{+}(16.66), 213\left[\mathrm{C}_{13} \mathrm{H}_{25} \mathrm{O}_{2}\right]^{+}(61.66), 199\left[\mathrm{C}_{12} \mathrm{H}_{23} \mathrm{O}_{2}\right]^{+}(16.66), 185 \\
{\left[\mathrm{C}_{11} \mathrm{H}_{21} \mathrm{O}_{2}\right]^{+}(33.33), 171\left[\mathrm{C}_{10} \mathrm{H}_{19} \mathrm{O}_{2}\right]^{+}(30), 157\left[\mathrm{C}_{9} \mathrm{H}_{17} \mathrm{O}_{2}\right]^{+}(33.33), 143\left[\mathrm{C}_{8} \mathrm{H}_{15} \mathrm{O}_{2}\right]^{+}(13.33), 129} \\
{\left[\mathrm{C}_{7} \mathrm{H}_{13} \mathrm{O}_{2}\right]^{+}(73.33), 115\left[\mathrm{C}_{6} \mathrm{H}_{11} \mathrm{O}_{2}\right]^{+}(23.33), 101\left[\mathrm{C}_{5} \mathrm{H}_{9} \mathrm{O}_{2}\right]^{+}(13.33), 87\left[\mathrm{C}_{4} \mathrm{H}_{7} \mathrm{O}_{2}\right]^{+}(23.33), 73} \\
{\left[\mathrm{C}_{3} \mathrm{H}_{5} \mathrm{O}_{2}\right]^{+}(100), 60\left[\mathrm{C}_{2} \mathrm{H}_{4} \mathrm{O}_{2}\right](68.33) .}\end{array}$ \\
\hline heptadecanoic acid & $\begin{array}{l}270[\mathrm{M}]^{+}(13.33), 241\left[\mathrm{C}_{15} \mathrm{H}_{29} \mathrm{O}_{2}\right]^{+}(3.33), 227\left[\mathrm{C}_{14} \mathrm{H}_{27} \mathrm{O}_{2}\right]^{+}(15), 213\left[\mathrm{C}_{13} \mathrm{H}_{25} \mathrm{O}_{2}\right]^{+}(15), 199 \\
{\left[\mathrm{C}_{12} \mathrm{H}_{23} \mathrm{O}_{2}\right]^{+}(6.66), 185\left[\mathrm{C}_{11} \mathrm{H}_{21} \mathrm{O}_{2}\right]^{+}(21.66), 171\left[\mathrm{C}_{10} \mathrm{H}_{19} \mathrm{O}_{2}\right]^{+}(16.66), 157\left[\mathrm{C}_{9} \mathrm{H}_{17} \mathrm{O}_{2}\right]^{+}(10), 143} \\
{\left[\mathrm{C}_{8} \mathrm{H}_{15} \mathrm{O}_{2}\right]^{+}(7), 129\left[\mathrm{C}_{7} \mathrm{H}_{13} \mathrm{O}_{2}\right]^{+}(43.33), 111\left[\mathrm{C}_{8} \mathrm{H}_{15}\right]^{+}(16.66), 101\left[\mathrm{C}_{5} \mathrm{H}_{9} \mathrm{O}_{2}\right]^{+}(10), 95(58.33), 73} \\
{\left[\mathrm{C}_{3} \mathrm{H}_{5} \mathrm{O}_{2}\right]^{+}(80), 55\left[\mathrm{C}_{4} \mathrm{H}_{7}\right]^{+}(100) .}\end{array}$ \\
\hline
\end{tabular}


$(\mathrm{Z}, \mathrm{Z}) 9,12-$

octadecadienoic acid

(E,E)9,12-

octadecadienoic acid

methyl $(Z, Z, Z) 9,12,15-$ octadecatrienoate

methyl tetradecanoate

methyl

pentadecanoate

methyl hexadecanoate

methyl octadecanoate

methyl eicosanoate

methyl docosanoate

methyl tricosanoate

methylhexadecanoate

methyl 9-eicosenoate
$280[\mathrm{M}]^{+}(5), 263\left[\mathrm{C}_{18} \mathrm{H}_{31} \mathrm{O}\right]^{+}(6.66), 237\left[\mathrm{C}_{15} \mathrm{H}_{25} \mathrm{O}_{2}\right]^{+}(1.66), 223\left[\mathrm{C}_{14} \mathrm{H}_{23} \mathrm{O}_{2}\right]^{+}(6.66), 209\left[\mathrm{C}_{13} \mathrm{H}_{21} \mathrm{O}_{2}\right]^{+}(3.3$ 3),183[ $\left.\mathrm{C}_{11} \mathrm{H}_{21} \mathrm{O}_{2}\right](6.66), 165\left[\mathrm{C}_{12} \mathrm{H}_{21}\right]^{+}(3.33), 149\left[\mathrm{C}_{11} \mathrm{H}_{17}\right]^{+}(10), 143\left[\mathrm{C}_{8} \mathrm{H}_{15} \mathrm{O}_{2}\right]^{+}(5), 137\left[\mathrm{C}_{10} \mathrm{H}_{17}\right]^{+}(11.6$ 6), $129\left[\mathrm{C}_{7} \mathrm{H}_{13} \mathrm{O}_{2}\right]^{+}(20), 115\left[\mathrm{C}_{6} \mathrm{H}_{11} \mathrm{O}_{2}\right]^{+}(10), 110\left[\mathrm{C}_{8} \mathrm{H}_{14}\right]^{+}(18.33), 95\left[\mathrm{C}_{7} \mathrm{H}_{11}\right]^{+}(75), 55\left[\mathrm{C}_{4} \mathrm{H}_{7}\right]^{+}(100)$,

$280[\mathrm{M}]^{+}$(6.66), $265\left[\mathrm{C}_{17} \mathrm{H}_{29} \mathrm{O}_{2}\right]^{+}(5), 235\left[\mathrm{C}_{17} \mathrm{H}_{31}\right]^{+}(1.66), 222\left[\mathrm{C}_{14} \mathrm{H}_{22} \mathrm{O}_{2}\right]^{+}(10), 209\left[\mathrm{C}_{13} \mathrm{H}_{21} \mathrm{O}_{2}\right]^{+}$ (3.33), $185\left[\mathrm{C}_{11} \mathrm{H}_{21} \mathrm{O}_{2}\right](3.33), 169\left[\mathrm{C}_{10} \mathrm{H}_{17} \mathrm{O}_{2}\right]^{+}(1.66), 165\left[\mathrm{C}_{12} \mathrm{H}_{21}\right]^{+}(1.66), 149\left[\mathrm{C}_{11} \mathrm{H}_{17}\right]^{+}(10), 143$ $\left[\mathrm{C}_{8} \mathrm{H}_{15} \mathrm{O}_{2}\right]^{+}(3), 135\left[\mathrm{C}_{10} \mathrm{H}_{15}\right]^{+}(13.33), 129\left[\mathrm{C}_{7} \mathrm{H}_{13} \mathrm{O}_{2}\right]^{+}(10), 97\left[\mathrm{C}_{7} \mathrm{H}_{13}\right]^{+}(66.66), 79(100), 55\left[\mathrm{C}_{4} \mathrm{H}_{7}\right]^{+}$ (70).

$278[\mathrm{M}]^{+}(6.66), 263\left[\mathrm{C}_{17} \mathrm{H}_{27} \mathrm{O}_{2}\right]^{+}(5), 249\left[\mathrm{C}_{16} \mathrm{H}_{25} \mathrm{O}_{2}\right]^{+}(3.33), 222\left[\mathrm{C}_{14} \mathrm{H}_{22} \mathrm{O}_{2}\right]^{+}(13.33), 185$ $\left[\mathrm{C}_{11} \mathrm{H}_{21} \mathrm{O}_{2}\right](3), 163\left[\mathrm{C}_{12} \mathrm{H}_{19}\right]^{+}(3.33), 149\left[\mathrm{C}_{11} \mathrm{H}_{17}\right]^{+}(10), 135\left[\mathrm{C}_{10} \mathrm{H}_{15}\right]^{+}(13.33), 108\left[\mathrm{C}_{8} \mathrm{H}_{12}\right]^{+}$ $(41.66), 95\left[\mathrm{C}_{7} \mathrm{H}_{11}\right]^{+}(53.33), 79(100), 69\left[\mathrm{C}_{5} \mathrm{H}_{9}\right]^{+}(60), 55\left[\mathrm{C}_{4} \mathrm{H}_{7}\right]^{+}(43.33)$.

$242[\mathrm{M}]^{+}$(6.88), $211\left[\mathrm{C}_{14} \mathrm{H}_{27} \mathrm{O}\right]^{+}(4.44), 199\left[\mathrm{C}_{12} \mathrm{H}_{23} \mathrm{O}_{2}\right]^{+}(11.11), 185\left[\mathrm{C}_{11} \mathrm{H}_{21} \mathrm{O}_{2}\right]^{+}(4.44), 171$ $\left[\mathrm{C}_{10} \mathrm{H}_{19} \mathrm{O}_{2}\right]^{+}(2.22), 157\left[\mathrm{C}_{9} \mathrm{H}_{17} \mathrm{O}_{2}\right]^{+}(4.44), 143\left[\mathrm{C}_{8} \mathrm{H}_{15} \mathrm{O}_{2}\right]^{+}(20), 129\left[\mathrm{C}_{7} \mathrm{H}_{13} \mathrm{O}_{2}\right]^{+}(6.66), 115$ $\left[\mathrm{C}_{6} \mathrm{H}_{11} \mathrm{O}_{2}\right]^{+}(2.22), 101\left[\mathrm{C}_{5} \mathrm{H}_{9} \mathrm{O}_{2}\right]^{+}(6.88), 87\left[\mathrm{C}_{4} \mathrm{H}_{7} \mathrm{O}_{2}\right]^{+}(62.44), 74\left[\mathrm{C}_{3} \mathrm{H}_{6} \mathrm{O}_{2}\right](100), 55\left[\mathrm{C}_{4} \mathrm{H}_{7}\right]^{+}$ (26.88).

$256[\mathrm{M}]^{+}$(8.88), $227\left[\mathrm{C}_{14} \mathrm{H}_{27} \mathrm{O}_{2}\right]^{+}(4.44), 213\left[\mathrm{C}_{13} \mathrm{H}_{25} \mathrm{O}_{2}\right]^{+}$(7.77), $199\left[\mathrm{C}_{12} \mathrm{H}_{23} \mathrm{O}_{2}\right]^{+}$(4.44), 185 $\left[\mathrm{C}_{11} \mathrm{H}_{21} \mathrm{O}_{2}\right]^{+}$(3.33), $171\left[\mathrm{C}_{10} \mathrm{H}_{19} \mathrm{O}_{2}\right]^{+}(3.33), 157\left[\mathrm{C}_{9} \mathrm{H}_{17} \mathrm{O}_{2}\right]^{+}(5.55), 143\left[\mathrm{C}_{8} \mathrm{H}_{15} \mathrm{O}_{2}\right]^{+}(17.77), 129$ $\left[\mathrm{C}_{7} \mathrm{H}_{13} \mathrm{O}_{2}\right]^{+}(6.66), 115\left[\mathrm{C}_{6} \mathrm{H}_{11} \mathrm{O}_{2}\right]^{+}(2.44), 101\left[\mathrm{C}_{5} \mathrm{H}_{9} \mathrm{O}_{2}\right]^{+}(6.66), 87\left[\mathrm{C}_{4} \mathrm{H}_{7} \mathrm{O}_{2}\right]^{+}(62.44), 74\left[\mathrm{C}_{3} \mathrm{H}_{6} \mathrm{O}_{2}\right]$ (100), $55\left[\mathrm{C}_{4} \mathrm{H}_{7}\right]^{+}$(27.77).

$270[\mathrm{M}]^{+}(11.11), 227\left[\mathrm{C}_{14} \mathrm{H}_{27} \mathrm{O}_{2}\right]^{+}(7.77), 213\left[\mathrm{C}_{13} \mathrm{H}_{25} \mathrm{O}_{2}\right]^{+}(2.22), 199\left[\mathrm{C}_{12} \mathrm{H}_{23} \mathrm{O}_{2}\right]^{+}(4.44), 185$ $\left[\mathrm{C}_{11} \mathrm{H}_{21} \mathrm{O}_{2}\right]^{+}$(5.55), $171\left[\mathrm{C}_{10} \mathrm{H}_{19} \mathrm{O}_{2}\right]^{+}(6.66), 157\left[\mathrm{C}_{9} \mathrm{H}_{17} \mathrm{O}_{2}\right]^{+}(3.33), 143\left[\mathrm{C}_{8} \mathrm{H}_{15} \mathrm{O}_{2}\right]^{+}$(17.77), 129 $\left[\mathrm{C}_{7} \mathrm{H}_{13} \mathrm{O}_{2}\right]^{+}(8.88), 115\left[\mathrm{C}_{6} \mathrm{H}_{11} \mathrm{O}_{2}\right]^{+}(4.44), 101\left[\mathrm{C}_{5} \mathrm{H}_{9} \mathrm{O}_{2}\right]^{+}(6.66), 87\left[\mathrm{C}_{4} \mathrm{H}_{7} \mathrm{O}_{2}\right]^{+}(64.44), 74\left[\mathrm{C}_{3} \mathrm{H}_{6} \mathrm{O}_{2}\right]$ $(100), 55\left[\mathrm{C}_{4} \mathrm{H}_{7}\right]^{+}(30)$.

$298[\mathrm{M}]^{+}(14.44), 281\left[\mathrm{C}_{18} \mathrm{H}_{33} \mathrm{O}_{2}\right]^{+}(1.11), 241\left[\mathrm{C}_{17} \mathrm{H}_{37}\right](2.44), 255\left[\mathrm{C}_{16} \mathrm{H}_{31} \mathrm{O}_{2}\right]^{+}(8.88), 241$ $\left[\mathrm{C}_{15} \mathrm{H}_{29} \mathrm{O}_{2}\right]^{+}(2.44), 199\left[\mathrm{C}_{12} \mathrm{H}_{23} \mathrm{O}_{2}\right]^{+}(8.88), 185\left[\mathrm{C}_{11} \mathrm{H}_{21} \mathrm{O}_{2}\right]^{+}(5.55), 171\left[\mathrm{C}_{10} \mathrm{H}_{19} \mathrm{O}_{2}\right]^{+}(2.22), 157$ $\left[\mathrm{C}_{9} \mathrm{H}_{17} \mathrm{O}_{2}\right]^{+}(4.44), 143\left[\mathrm{C}_{8} \mathrm{H}_{15} \mathrm{O}_{2}\right]^{+}(22.22), 129\left[\mathrm{C}_{7} \mathrm{H}_{13} \mathrm{O}_{2}\right]^{+}(13.33), 117\left[\mathrm{C}_{6} \mathrm{H}_{13} \mathrm{O}_{2}\right]$ (7.77), 101 $\left[\mathrm{C}_{5} \mathrm{H}_{9} \mathrm{O}_{2}\right]^{+}(7.77), 97\left[\mathrm{C}_{7} \mathrm{H}_{13}\right]^{+}(14.44), 87\left[\mathrm{C}_{4} \mathrm{H}_{7} \mathrm{O}_{2}\right]^{+}(67.77), 74\left[\mathrm{C}_{3} \mathrm{H}_{6} \mathrm{O}_{2}\right](100), 55\left[\mathrm{C}_{4} \mathrm{H}_{7}\right]^{+}$(47.77).

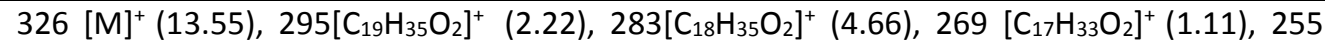
$\left[\mathrm{C}_{16} \mathrm{H}_{31} \mathrm{O}_{2}\right]^{+}(2), 241\left[\mathrm{C}_{15} \mathrm{H}_{29} \mathrm{O}_{2}\right]^{+}(2.22), 227\left[\mathrm{C}_{14} \mathrm{H}_{27} \mathrm{O}_{2}\right]^{+}(2.44), 213\left[\mathrm{C}_{13} \mathrm{H}_{25} \mathrm{O}_{2}\right]^{+}(2), 199$ $\left[\mathrm{C}_{12} \mathrm{H}_{23} \mathrm{O}_{2}\right]^{+}(3.33), 185\left[\mathrm{C}_{11} \mathrm{H}_{21} \mathrm{O}_{2}\right]^{+}(2.44), 171\left[\mathrm{C}_{10} \mathrm{H}_{19} \mathrm{O}_{2}\right]^{+}(2.22), 157\left[\mathrm{C}_{9} \mathrm{H}_{17} \mathrm{O}_{2}\right]^{+}(2.22), 143$ $\left[\mathrm{C}_{8} \mathrm{H}_{15} \mathrm{O}_{2}\right]^{+}(15.55), 129\left[\mathrm{C}_{7} \mathrm{H}_{13} \mathrm{O}_{2}\right]^{+}(6.88), 115\left[\mathrm{C}_{6} \mathrm{H}_{11} \mathrm{O}_{2}\right]^{+}(2.44), 101\left[\mathrm{C}_{5} \mathrm{H}_{9} \mathrm{O}_{2}\right]^{+}(6.66), 97\left[\mathrm{C}_{7} \mathrm{H}_{13}\right]^{+}$ $(11.55), 87\left[\mathrm{C}_{4} \mathrm{H}_{7} \mathrm{O}_{2}\right]^{+}(65.55), 74\left[\mathrm{C}_{3} \mathrm{H}_{6} \mathrm{O}_{2}\right](100), 55\left[\mathrm{C}_{4} \mathrm{H}_{7}\right]^{+}(40)$.

$354[\mathrm{M}]^{+}(20), 323\left[\mathrm{C}_{22} \mathrm{H}_{43} \mathrm{O}\right]^{+}(2.22), 311\left[\mathrm{C}_{20} \mathrm{H}_{39} \mathrm{O}_{2}\right]^{+}(6.66), 297\left[\mathrm{C}_{19} \mathrm{H}_{37} \mathrm{O}_{2}\right]^{+}(2), 283\left[\mathrm{C}_{18} \mathrm{H}_{35} \mathrm{O}_{2}\right]^{+}$ $(0.44), 269\left[\mathrm{C}_{17} \mathrm{H}_{33} \mathrm{O}_{2}\right]^{+}(2.22), 255\left[\mathrm{C}_{16} \mathrm{H}_{31} \mathrm{O}_{2}\right]^{+}(4.44), 241\left[\mathrm{C}_{15} \mathrm{H}_{29} \mathrm{O}_{2}\right]^{+}(2.22), 227\left[\mathrm{C}_{14} \mathrm{H}_{27} \mathrm{O}_{2}\right]^{+}$ (1.11), $213\left[\mathrm{C}_{13} \mathrm{H}_{25} \mathrm{O}_{2}\right]^{+}(2), 199\left[\mathrm{C}_{12} \mathrm{H}_{23} \mathrm{O}_{2}\right]^{+}(4.44), 185\left[\mathrm{C}_{11} \mathrm{H}_{21} \mathrm{O}_{2}\right]^{+}(2.44), 171\left[\mathrm{C}_{10} \mathrm{H}_{19} \mathrm{O}_{2}\right]^{+}(2)$, $157\left[\mathrm{C}_{9} \mathrm{H}_{17} \mathrm{O}_{2}\right]^{+}$(2.22), $143\left[\mathrm{C}_{8} \mathrm{H}_{15} \mathrm{O}_{2}\right]^{+}(18.88), 129\left[\mathrm{C}_{7} \mathrm{H}_{13} \mathrm{O}_{2}\right]^{+}(8.88), 115\left[\mathrm{C}_{6} \mathrm{H}_{11} \mathrm{O}_{2}\right]^{+}(2.44), 101$ $\left[\mathrm{C}_{5} \mathrm{H}_{9} \mathrm{O}_{2}\right]^{+}(7.77), 97\left[\mathrm{C}_{7} \mathrm{H}_{13}\right]^{+}(14.44), 87\left[\mathrm{C}_{4} \mathrm{H}_{7} \mathrm{O}_{2}\right]^{+}(78.88), 74\left[\mathrm{C}_{3} \mathrm{H}_{6} \mathrm{O}_{2}\right](100), 55\left[\mathrm{C}_{4} \mathrm{H}_{7}\right]^{+}(44.44)$. $368[\mathrm{M}]^{+}(18.88), 355\left[\mathrm{C}_{23} \mathrm{H}_{47} \mathrm{O}_{2}\right]^{+}(0.22), 337\left[\mathrm{C}_{23} \mathrm{H}_{45} \mathrm{O}\right]^{+}(2.22), 325\left[\mathrm{C}_{21} \mathrm{H}_{41} \mathrm{O}_{2}\right]^{+}$(5.55), 311 $\left[\mathrm{C}_{20} \mathrm{H}_{39} \mathrm{O}_{2}\right]^{+}(2), 297\left[\mathrm{C}_{19} \mathrm{H}_{37} \mathrm{O}_{2}\right]^{+}(0.44), 283\left[\mathrm{C}_{18} \mathrm{H}_{35} \mathrm{O}_{2}\right]^{+}(2.22), 269\left[\mathrm{C}_{17} \mathrm{H}_{33} \mathrm{O}_{2}\right]^{+}(3.33), 255$ $\left[\mathrm{C}_{16} \mathrm{H}_{31} \mathrm{O}_{2}\right]^{+}(2), 241\left[\mathrm{C}_{15} \mathrm{H}_{29} \mathrm{O}_{2}\right]^{+}(2), 227\left[\mathrm{C}_{14} \mathrm{H}_{27} \mathrm{O}_{2}\right]^{+}(2), 213\left[\mathrm{C}_{13} \mathrm{H}_{25} \mathrm{O}_{2}\right]^{+}(2.22), 199\left[\mathrm{C}_{12} \mathrm{H}_{23} \mathrm{O}_{2}\right]^{+}$ (4.22), $185\left[\mathrm{C}_{11} \mathrm{H}_{21} \mathrm{O}_{2}\right]^{+}(2.66), 171\left[\mathrm{C}_{10} \mathrm{H}_{19} \mathrm{O}_{2}\right]^{+}(2), 157\left[\mathrm{C}_{9} \mathrm{H}_{17} \mathrm{O}_{2}\right]^{+}(2.22), 143\left[\mathrm{C}_{8} \mathrm{H}_{15} \mathrm{O}_{2}\right]^{+}(20)$, $129\left[\mathrm{C}_{7} \mathrm{H}_{13} \mathrm{O}_{2}\right]^{+}(8.88), 115\left[\mathrm{C}_{6} \mathrm{H}_{11} \mathrm{O}_{2}\right]^{+}(3.33), 101\left[\mathrm{C}_{5} \mathrm{H}_{9} \mathrm{O}_{2}\right]^{+}(7.11), 97\left[\mathrm{C}_{7} \mathrm{H}_{13}\right]^{+}(15.77), 87$ $\left[\mathrm{C}_{4} \mathrm{H}_{7} \mathrm{O}_{2}\right]^{+}(71.33), 74\left[\mathrm{C}_{3} \mathrm{H}_{6} \mathrm{O}_{2}\right](100), 55\left[\mathrm{C}_{4} \mathrm{H}_{7}\right]^{+}(44.44)$.

methyl tetracosanoate $382[\mathrm{M}]^{+}(22.22), 351\left[\mathrm{C}_{24} \mathrm{H}_{47} \mathrm{O}\right]^{+}(2.22), 339\left[\mathrm{C}_{22} \mathrm{H}_{43} \mathrm{O}_{2}\right]^{+}(6.44), 325\left[\mathrm{C}_{21} \mathrm{H}_{41} \mathrm{O}_{2}\right]^{+}(1.11), 311$ $\left[\mathrm{C}_{20} \mathrm{H}_{39} \mathrm{O}_{2}\right]^{+}(1.11), 297\left[\mathrm{C}_{19} \mathrm{H}_{37} \mathrm{O}_{2}\right]^{+}(2.22), 283\left[\mathrm{C}_{18} \mathrm{H}_{35} \mathrm{O}_{2}\right]^{+}$(3.33), $269\left[\mathrm{C}_{17} \mathrm{H}_{33} \mathrm{O}_{2}\right]^{+}$(1.11), 255 $\left[\mathrm{C}_{16} \mathrm{H}_{31} \mathrm{O}_{2}\right]^{+}(2.22), 241\left[\mathrm{C}_{15} \mathrm{H}_{29} \mathrm{O}_{2}\right]^{+}(2.22), 227\left[\mathrm{C}_{14} \mathrm{H}_{27} \mathrm{O}_{2}\right]^{+}(2), 213\left[\mathrm{C}_{13} \mathrm{H}_{25} \mathrm{O}_{2}\right]^{+}(0.44), 199$ $\left[\mathrm{C}_{12} \mathrm{H}_{23} \mathrm{O}_{2}\right]^{+}(4.44), 185\left[\mathrm{C}_{11} \mathrm{H}_{21} \mathrm{O}_{2}\right]^{+}(3.33), 171\left[\mathrm{C}_{10} \mathrm{H}_{19} \mathrm{O}_{2}\right]^{+}(2), 157\left[\mathrm{C}_{9} \mathrm{H}_{17} \mathrm{O}_{2}\right]^{+}(2.22), 143$ $\left[\mathrm{C}_{8} \mathrm{H}_{15} \mathrm{O}_{2}\right]^{+}(22.22), 129\left[\mathrm{C}_{7} \mathrm{H}_{13} \mathrm{O}_{2}\right]^{+}(8.88), 115\left[\mathrm{C}_{6} \mathrm{H}_{11} \mathrm{O}_{2}\right]^{+}(2.66), 101\left[\mathrm{C}_{5} \mathrm{H}_{9} \mathrm{O}_{2}\right]^{+}(7.77), 97\left[\mathrm{C}_{7} \mathrm{H}_{13}\right]^{+}$ $(15.55), 87\left[\mathrm{C}_{4} \mathrm{H}_{7} \mathrm{O}_{2}\right]^{+}(77.77), 74\left[\mathrm{C}_{3} \mathrm{H}_{6} \mathrm{O}_{2}\right](100), 55\left[\mathrm{C}_{4} \mathrm{H}_{7}\right]^{+}(43.33)$.

$284[\mathrm{M}]^{+}(10), 253\left[\mathrm{C}_{17} \mathrm{H}_{33} \mathrm{O}\right]^{+}(3.33), 227\left[\mathrm{C}_{14} \mathrm{H}_{27} \mathrm{O}_{2}\right]^{+}(2.22), 213\left[\mathrm{C}_{13} \mathrm{H}_{25} \mathrm{O}_{2}\right]^{+}(2.22), 199$ $\left[\mathrm{C}_{12} \mathrm{H}_{23} \mathrm{O}_{2}\right]^{+}$(4.66), $185\left[\mathrm{C}_{11} \mathrm{H}_{21} \mathrm{O}_{2}\right]^{+}(6.66), 171\left[\mathrm{C}_{10} \mathrm{H}_{19} \mathrm{O}_{2}\right]^{+}(2.22), 157\left[\mathrm{C}_{9} \mathrm{H}_{17} \mathrm{O}_{2}\right]^{+}$(3.33), 143 $\left.\left[\mathrm{C}_{8} \mathrm{H}_{15} \mathrm{O}_{2}\right]^{+}(17.88), 129 \mathrm{C}_{7} \mathrm{H}_{13} \mathrm{O}_{2}\right]^{+}(10), 115\left[\mathrm{C}_{6} \mathrm{H}_{11} \mathrm{O}_{2}\right]^{+}(4.44), 101\left[\mathrm{C}_{5} \mathrm{H}_{9} \mathrm{O}_{2}\right]^{+}(7.77), 97\left[\mathrm{C}_{7} \mathrm{H}_{13}\right]^{+}$ $(12.22), 87\left[\mathrm{C}_{4} \mathrm{H}_{7} \mathrm{O}_{2}\right]^{+}(66.66), 74\left[\mathrm{C}_{3} \mathrm{H}_{6} \mathrm{O}_{2}\right]^{+}(100), 55\left[\mathrm{C}_{4} \mathrm{H}_{7}\right]^{+}(40)$.

$324[\mathrm{M}]^{+}(2.22), 292\left[\mathrm{C}_{20} \mathrm{H}_{36} \mathrm{O}\right]^{+}(13.33), 281\left[\mathrm{C}_{18} \mathrm{H}_{33} \mathrm{O}_{2}\right]^{+}(0.22), 263\left[\mathrm{C}_{19} \mathrm{H}_{35}\right]^{+}(1.11), 250$ $\left[\mathrm{C}_{18} \mathrm{H}_{34}\right]^{+}(4.44), 237\left[\mathrm{C}_{17} \mathrm{H}_{33}\right]^{+}(2), 223\left[\mathrm{C}_{16} \mathrm{H}_{31}\right]^{+}(2.22), 208\left[\mathrm{C}_{15} \mathrm{H}_{28}\right]^{+}(4.44), 195\left[\mathrm{C}_{14} \mathrm{H}_{27}\right]^{+}(2.22)$, $185\left[\mathrm{C}_{11} \mathrm{H}_{21} \mathrm{O}_{2}\right]^{+}(1.11), 179\left[\mathrm{C}_{13} \mathrm{H}_{23}\right]^{+}(2.22), 171\left[\mathrm{C}_{10} \mathrm{H}_{19} \mathrm{O}_{2}\right]^{+}(1.11), 167\left[\mathrm{C}_{12} \mathrm{H}_{23}\right]^{+}$(4.44), 157 $\left[\mathrm{C}_{9} \mathrm{H}_{17} \mathrm{O}_{2}\right]^{+}(2), 152\left[\mathrm{C}_{11} \mathrm{H}_{20}\right]^{+}(4.66), 143\left[\mathrm{C}_{8} \mathrm{H}_{15} \mathrm{O}_{2}\right]^{+}(3.33), 139\left[\mathrm{C}_{10} \mathrm{H}_{19}\right]^{+}(5.55), 129\left[\mathrm{C}_{7} \mathrm{H}_{13} \mathrm{O}_{2}\right]^{+}$ 


\begin{tabular}{|c|c|}
\hline & $\begin{array}{l}\text { (4.44), } 123(11.11), 115\left[\mathrm{C}_{6} \mathrm{H}_{11} \mathrm{O}_{2}\right]^{+}(4.44), 111\left[\mathrm{C}_{8} \mathrm{H}_{15}\right]^{+}(17.77), 101\left[\mathrm{C}_{5} \mathrm{H}_{9} \mathrm{O}_{2}\right]^{+}(4.66), 97\left[\mathrm{C}_{7} \mathrm{H}_{13}\right]^{+} \\
(40), 83\left[\mathrm{C}_{6} \mathrm{H}_{11}\right]^{+}(48.88), 69\left[\mathrm{C}_{5} \mathrm{H}_{9}\right]^{+}(64.44), 55\left[\mathrm{C}_{4} \mathrm{H}_{7}\right]^{+}(100) .\end{array}$ \\
\hline $\begin{array}{l}\text { methyl }(\mathrm{Z}, \mathrm{Z}) 7,10- \\
\text { methyloctadecadienoa } \\
\text { te }\end{array}$ & $\begin{array}{l}294[\mathrm{M}]^{+}(13.33), 264\left[\mathrm{C}_{17} \mathrm{H}_{28} \mathrm{O}_{2}\right]^{+}(16.66), 237\left[\mathrm{C}_{15} \mathrm{H}_{25} \mathrm{O}_{2}\right]^{+}(3.33), 222\left[\mathrm{C}_{14} \mathrm{H}_{22} \mathrm{O}_{2}\right]^{+}(6.88), 207 \\
{\left[\mathrm{C}_{15} \mathrm{H}_{27}\right]^{+}(2.22), 193\left[\mathrm{C}_{14} \mathrm{H}_{25}\right]^{+}(2.22), 180\left[\mathrm{C}_{13} \mathrm{H}_{24}\right]^{+}(6.88), 169\left[\mathrm{C}_{10} \mathrm{H}_{17} \mathrm{O}_{2}\right]^{+}(2), 164\left[\mathrm{C}_{12} \mathrm{H}_{20}\right]^{+}} \\
(8.88), 155\left[\mathrm{C}_{9} \mathrm{H}_{15} \mathrm{O}_{2}\right]^{+}(1.11), 149\left[\mathrm{C}_{11} \mathrm{H}_{17}\right]^{+}(17.77), 143\left[\mathrm{C}_{8} \mathrm{H}_{15} \mathrm{O}_{2}\right]^{+}(4.66), 135\left[\mathrm{C}_{10} \mathrm{H}_{15}\right]^{+}(22.22), 101 \\
129\left[\mathrm{C}_{7} \mathrm{H}_{13} \mathrm{O}_{2}\right]^{+}(6.66), 125\left[\mathrm{C}_{9} \mathrm{H}_{17}\right]^{+}(8.88), 115\left[\mathrm{C}_{6} \mathrm{H}_{11} \mathrm{O}_{2}\right]^{+}(6.66), 109\left[\mathrm{C}_{8} \mathrm{H}_{13}\right]^{+}(31.11), 101 \\
{\left[\mathrm{C}_{5} \mathrm{H}_{9} \mathrm{O}_{2}\right]^{+}(6.66), 95\left[\mathrm{C}_{7} \mathrm{H}_{11}\right]^{+}(75.55), 81(88.88), 67(100), 55\left[\mathrm{C}_{4} \mathrm{H}_{7}\right]^{+}(82.66) .}\end{array}$ \\
\hline $\begin{array}{l}\text { methyl } \quad(\mathrm{Z}, \mathrm{Z}) 8,11- \\
\text { octadecadienoate }\end{array}$ & $\begin{array}{l}294\left[\mathrm{MM}^{+}(6.66), 264\left[\mathrm{C}_{17} \mathrm{H}_{28} \mathrm{O}_{2}\right]^{+}(6.66), 237\left[\mathrm{C}_{15} \mathrm{H}_{25} \mathrm{O}_{2}\right]^{+}(1.11), 222\left[\mathrm{C}_{14} \mathrm{H}_{22} \mathrm{O}_{2}\right]^{+}(2.66), 193\right. \\
{\left[\mathrm{C}_{14} \mathrm{H}_{25}\right]^{+}(1.11), 185\left[\mathrm{C}_{11} \mathrm{H}_{21} \mathrm{O}_{2}\right]^{+}(2), 180\left[\mathrm{C}_{13} \mathrm{H}_{24}\right]^{+}(3.33), 164\left[\mathrm{C}_{12} \mathrm{H}_{20}\right]^{+}(5.55), 157\left[\mathrm{C}_{9} \mathrm{H}_{17} \mathrm{O}_{2}\right]^{+}} \\
(2.22), 149\left[\mathrm{C}_{11} \mathrm{H}_{17}\right]^{+}(10.88), 143\left[\mathrm{C}_{8} \mathrm{H}_{15} \mathrm{O}_{2}\right]^{+}(4.22), 135\left[\mathrm{C}_{10} \mathrm{H}_{15}\right]^{+}(13.55), 129\left[\mathrm{C}_{7} \mathrm{H}_{13} \mathrm{O}_{2}\right]^{+}(7.11), \\
125\left[\mathrm{C}_{9} \mathrm{H}_{17}\right]^{+}(11.11), 115\left[\mathrm{C}_{6} \mathrm{H}_{11} \mathrm{O}_{2}\right]^{+}(5.55), 109\left[\mathrm{C}_{8} \mathrm{H}_{13}\right]^{+}(26.66), 101\left[\mathrm{C}_{5} \mathrm{H}_{9} \mathrm{O}_{2}\right]^{+}(4.66), 95 \\
{\left[\mathrm{C}_{7} \mathrm{H}_{11}\right]^{+}(58.88), 81(79.77), 67\left[\mathrm{C}_{5} \mathrm{H}_{7}\right]^{+}(100), 55\left[\mathrm{C}_{4} \mathrm{H}_{7}\right]^{+}(84.44) .}\end{array}$ \\
\hline $\begin{array}{l}\text { methyl } \quad(Z, Z) 9,12- \\
\text { octadecadienoate }\end{array}$ & $\begin{array}{l}294[\mathrm{M}]^{+}(2.44), 265\left[\mathrm{C}_{17} \mathrm{H}_{28} \mathrm{O}_{2}\right]^{+}(5.55), 237\left[\mathrm{C}_{15} \mathrm{H}_{25} \mathrm{O}_{2}\right]^{+}(2.44), 222\left[\mathrm{C}_{14} \mathrm{H}_{22} \mathrm{O}_{2}\right]^{+}(5.55), 207 \\
{\left[\mathrm{C}_{15} \mathrm{H}_{27}\right]^{+}(1.11), 193\left[\mathrm{C}_{14} \mathrm{H}_{25}\right]^{+}(2), 185\left[\mathrm{C}_{11} \mathrm{H}_{21} \mathrm{O}_{2}\right](2.22), 180\left[\mathrm{C}_{13} \mathrm{H}_{24}\right]^{+}(6.66), 164\left[\mathrm{C}_{12} \mathrm{H}_{20}\right]^{+}} \\
(4.44), 157\left[\mathrm{C}_{9} \mathrm{H}_{17} \mathrm{O}_{2}\right]^{+}(2.66), 149\left[\mathrm{C}_{11} \mathrm{H}_{17}\right]^{+}(11.11), 143\left[\mathrm{C}_{8} \mathrm{H}_{15} \mathrm{O}_{2}\right]^{+}(4.44), 135\left[\mathrm{C}_{10} \mathrm{H}_{15}\right]^{+}(15.55), \\
129\left[\mathrm{C}_{7} \mathrm{H}_{13} \mathrm{O}_{2}\right]^{+}(11.11), 115\left[\mathrm{C}_{6} \mathrm{H}_{11} \mathrm{O}_{2}\right]^{+}(6.88), 109\left[\mathrm{C}_{8} \mathrm{H}_{13}\right]^{+}(31.11), 101\left[\mathrm{C}_{5} \mathrm{H}_{9} \mathrm{O}_{2}\right]^{+}(6.88), 95 \\
{\left[\mathrm{C}_{7} \mathrm{H}_{11}\right]^{+}(60.22), 79(80), 67\left[\mathrm{C}_{5} \mathrm{H}_{7}\right]^{+}(98), 55\left[\mathrm{C}_{4} \mathrm{H}_{7}\right]^{+}(100) .}\end{array}$ \\
\hline $\begin{array}{l}\text { methyl } \quad(Z, E) 9,11- \\
\text { octadecadienoate }\end{array}$ & $\begin{array}{l}294[\mathrm{M}]^{+}(8.88), 263\left[\mathrm{C}_{18} \mathrm{H}_{31} \mathrm{O}\right]^{+}(4.44), 220\left[\mathrm{C}_{16} \mathrm{H}_{28}\right]^{+}(2.22), 192\left[\mathrm{C}_{14} \mathrm{H}_{24}\right]^{+}(2.22), 179\left[\mathrm{C}_{13} \mathrm{H}_{23}\right]^{+} \\
(4.44), 164\left[\mathrm{C}_{12} \mathrm{H}_{20}\right]^{+}(6.66), 135\left[\mathrm{C}_{10} \mathrm{H}_{15}\right]^{+}(13.33), 109\left[\mathrm{C}_{8} \mathrm{H}_{13}\right]^{+}(26.66), 95\left[\mathrm{C}_{7} \mathrm{H}_{11}\right]^{+}(58.88), 81 \\
{\left[\mathrm{C}_{6} \mathrm{H}_{9}\right]^{+}(84.44), 67\left[\mathrm{C}_{5} \mathrm{H}_{7}\right]^{+}(100), 55\left[\mathrm{C}_{4} \mathrm{H}_{7}\right]^{+}(64.44) .}\end{array}$ \\
\hline $\begin{array}{l}\text { methyl }(\mathrm{Z}, \mathrm{Z}, \mathrm{Z}) 9,12,15- \\
\text { octadecatrienoate }\end{array}$ & $\begin{array}{l}292[\mathrm{M}]^{+}(3.33), 263\left[\mathrm{C}_{17} \mathrm{H}_{27} \mathrm{O}_{2}\right]^{+}(5), 237\left[\mathrm{C}_{15} \mathrm{H}_{25} \mathrm{O}_{2}\right]^{+}(3.33), 222\left[\mathrm{C}_{14} \mathrm{H}_{22} \mathrm{O}_{2}\right]^{+}(6.66), 197 \\
{\left[\mathrm{C}_{12} \mathrm{H}_{21} \mathrm{O}_{2}\right]^{+}(1.66), 185\left[\mathrm{C}_{11} \mathrm{H}_{21} \mathrm{O}_{2}\right](5), 177\left[\mathrm{C}_{13} \mathrm{H}_{21}\right]^{+}(1.66), 163\left[\mathrm{C}_{12} \mathrm{H}_{19}\right]^{+}(3.33), 157\left[\mathrm{C}_{9} \mathrm{H}_{17} \mathrm{O}_{2}\right]^{+}} \\
(3.33), 149\left[\mathrm{C}_{11} \mathrm{H}_{17}\right]^{+}(11.66), 143\left[\mathrm{C}_{8} \mathrm{H}_{15} \mathrm{O}_{2}\right]^{+}(3.33), 135\left[\mathrm{C}_{10} \mathrm{H}_{15}\right]^{+}(15), 129\left[\mathrm{C}_{7} \mathrm{H}_{13} \mathrm{O}_{2}\right]^{+}(13.33), \\
108\left[\mathrm{C}_{8} \mathrm{H}_{12}\right]^{+}(38.33), 95\left[\mathrm{C}_{7} \mathrm{H}_{11}\right]^{+}(61.66), 79(100), 73\left[\mathrm{C}_{3} \mathrm{H}_{5} \mathrm{O}_{2}\right]^{+}(25), 69\left[\mathrm{C}_{5} \mathrm{H}_{9}\right]^{+}(73.33), 55 \\
{\left[\mathrm{C}_{4} \mathrm{H}_{7}\right]^{+}(66.66) .}\end{array}$ \\
\hline $\begin{array}{ll}\text { methyl } & \text { 9-oxo } \\
\text { nonanoate } & \end{array}$ & $\begin{array}{l}186[\mathrm{M}]^{+}(0.44), 158\left[\mathrm{C}_{9} \mathrm{H}_{18} \mathrm{O}_{2}\right]^{+}(15.55), 155\left[\mathrm{C}_{9} \mathrm{H}_{15} \mathrm{O}_{2}\right]^{+}(25.55), 143\left[\mathrm{C}_{8} \mathrm{H}_{15} \mathrm{O}_{2}\right]^{+}(42.22), 129 \\
{\left[\mathrm{C}_{7} \mathrm{H}_{13} \mathrm{O}_{2}\right]^{+}(4.44), 115\left[\mathrm{C}_{6} \mathrm{H}_{11} \mathrm{O}_{2}\right]^{+}(17.77), 111\left[\mathrm{C}_{7} \mathrm{H}_{11} \mathrm{O}\right]^{+}(57.77), 101\left[\mathrm{C}_{5} \mathrm{H}_{9} \mathrm{O}_{2}\right]^{+}(15.55), 98} \\
{\left[\mathrm{C}_{6} \mathrm{H}_{10} \mathrm{O}\right]^{+}(15.55), 87\left[\mathrm{C}_{4} \mathrm{H}_{7} \mathrm{O}_{2}\right]^{+}(84.44), 73\left[\mathrm{C}_{3} \mathrm{H}_{5} \mathrm{O}_{2}\right]^{+}(62.22), 59\left[\mathrm{C}_{2} \mathrm{H}_{3} \mathrm{O}_{2}\right]^{+}(40), 55\left[\mathrm{C}_{3} \mathrm{H}_{3} \mathrm{O}\right]^{+}} \\
(100) .\end{array}$ \\
\hline butyl hexadecanoate & $\begin{array}{l}312[\mathrm{M}]^{+}(8.88), 281\left[\mathrm{C}_{18} \mathrm{H}_{33} \mathrm{O}_{2}\right]^{+}(0.22), 269\left[\mathrm{C}_{17} \mathrm{H}_{33} \mathrm{O}_{2}\right]^{+}(2.22), 257\left[\mathrm{C}_{16} \mathrm{H}_{33} \mathrm{O}_{2}\right]^{+}(28.88), 239 \\
{\left[\mathrm{C}_{16} \mathrm{H}_{31} \mathrm{O}\right]^{+}(14.44), 227\left[\mathrm{C}_{14} \mathrm{H}_{27} \mathrm{O}_{2}\right]^{+}(2.44), 213\left[\mathrm{C}_{13} \mathrm{H}_{25} \mathrm{O}_{2}\right]^{+}(6.66), 199\left[\mathrm{C}_{12} \mathrm{H}_{23} \mathrm{O}_{2}\right]^{+}(2.22), 185} \\
{\left[\mathrm{C}_{11} \mathrm{H}_{21} \mathrm{O}_{2}\right]^{+}(7.77), 171\left[\mathrm{C}_{10} \mathrm{H}_{19} \mathrm{O}_{2}\right]^{+}(5.55), 157\left[\mathrm{C}_{9} \mathrm{H}_{17} \mathrm{O}_{2}\right]^{+}(4.44), 143\left[\mathrm{C}_{8} \mathrm{H}_{15} \mathrm{O}_{2}\right]^{+}(3.33), 129} \\
{\left[\mathrm{C}_{7} \mathrm{H}_{13} \mathrm{O}_{2}\right]^{+}(24.44), 117\left[\mathrm{C}_{6} \mathrm{H}_{13} \mathrm{O}_{2}\right](13.33), 101\left[\mathrm{C}_{5} \mathrm{H}_{9} \mathrm{O}_{2}\right]^{+}(12.22), 99\left[\mathrm{C}_{7} \mathrm{H}_{15}\right]^{+}(15.55), 83\left[\mathrm{C}_{6} \mathrm{H}_{11}\right]^{+}} \\
(20), 73\left[\mathrm{C}_{4} \mathrm{H}_{9} \mathrm{O}\right]^{+}(37.77), 56\left[\mathrm{C}_{4} \mathrm{H}_{8}\right]^{+}(100) .\end{array}$ \\
\hline $\begin{array}{l}\text { butyl } \quad(\mathrm{Z}, \mathrm{Z}) 9,12- \\
\text { octadecadienoate }\end{array}$ & 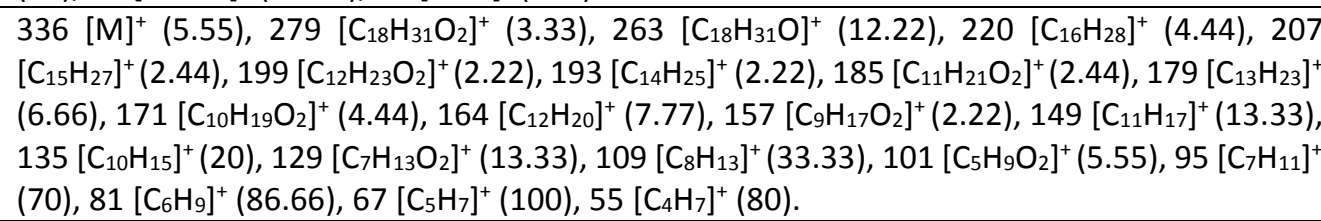 \\
\hline $\begin{array}{ll}\text { butyl } & 9,12,15- \\
\text { octadecatrienoate }\end{array}$ & $\begin{array}{l}334[\mathrm{M}]^{+}(4.44), 305\left[\mathrm{C}_{20} \mathrm{H}_{33} \mathrm{O}_{2}\right]^{+}(1.11), 277\left[\mathrm{C}_{18} \mathrm{H}_{29} \mathrm{O}_{2}\right]^{+}(2.22), 261\left[\mathrm{C}_{18} \mathrm{H}_{29} \mathrm{O}\right]^{+}(6.66), 231 \\
\left.\left[\mathrm{C}_{17} \mathrm{H}_{27}\right]^{+}(0.22), 191\left[\mathrm{C}_{14} \mathrm{H}_{23}\right]^{+}(3.55), 185\left[\mathrm{C}_{11} \mathrm{H}_{21} \mathrm{O}_{2}\right]^{+}(2.22), 177\left[\mathrm{C}_{13} \mathrm{H}_{21}\right]^{+}(2.22), 163\left[\mathrm{C}_{12} \mathrm{H}_{19}\right]^{+}\right]^{+} \\
(6.66), 149\left[\mathrm{C}_{11} \mathrm{H}_{17}\right]^{+}(15.55), 135\left[\mathrm{C}_{10} \mathrm{H}_{15}\right]^{+}(20), 129\left[\mathrm{C}_{7} \mathrm{H}_{13} \mathrm{O}_{2}\right]^{+}(7.77), 121\left[\mathrm{C}_{9} \mathrm{H}_{13}\right]^{+}(24.44), 108 \\
{\left[\mathrm{C}_{8} \mathrm{H}_{12}\right]^{+}(42.22), 95\left[\mathrm{C}_{7} \mathrm{H}_{11}\right]^{+}(63.33), 79\left[\mathrm{C}_{6} \mathrm{H}_{7}\right]^{+}(100), 67\left[\mathrm{C}_{5} \mathrm{H}_{7}\right]^{+}(73.33), 55\left[\mathrm{C}_{4} \mathrm{H}_{7}\right]^{+}(50) .}\end{array}$ \\
\hline $\begin{array}{l}\text { 2,3-dihydroxypropyl } \\
\text { hexadecanoate }\end{array}$ & $\begin{array}{l}330[\mathrm{M}]^{+}(1.11), 313\left[\mathrm{C}_{19} \mathrm{H}_{37} \mathrm{O}_{3}\right]^{+}(2.22), 273\left[\mathrm{C}_{15} \mathrm{H}_{29} \mathrm{O}_{4}\right]^{+}(1.11), 256\left[\mathrm{C}_{16} \mathrm{H}_{32} \mathrm{O}_{2}\right](4.66), 245 \\
{\left[\mathrm{C}_{13} \mathrm{H}_{25} \mathrm{O}_{4}\right]^{+}(1.11), 230\left[\mathrm{C}_{12} \mathrm{H}_{22} \mathrm{O}_{4}\right]^{+}(1.11), 213\left[\mathrm{C}_{15} \mathrm{H}_{33}\right](3.33), 197\left[\mathrm{C}_{14} \mathrm{H}_{29}\right]^{+}(4.44), 185\left[\mathrm{C}_{13} \mathrm{H}_{29}\right]} \\
(6.66), 171\left[\mathrm{C}_{12} \mathrm{H}_{27}\right](4.66), 155\left[\mathrm{C}_{11} \mathrm{H}_{23}\right]^{+}(6.66), 147\left[\mathrm{C}_{6} \mathrm{H}_{11} \mathrm{O}_{4}\right]^{+}(6.88), 141\left[\mathrm{C}_{10} \mathrm{H}_{21}\right]^{+}(8.88), 135 \\
{\left[\mathrm{C}_{5} \mathrm{H}_{11} \mathrm{O}_{4}\right](15.55), 129\left[\mathrm{C}_{9} \mathrm{H}_{21}\right](28.88), 117\left[\mathrm{C}_{4} \mathrm{H}_{5} \mathrm{O}_{4}\right]^{+}(22.22), 95\left[\mathrm{C}_{7} \mathrm{H}_{11}\right]^{+}(38.88), 85\left[\mathrm{C}_{6} \mathrm{H}_{13}\right]^{+}} \\
(47.77), 71\left[\mathrm{C}_{5} \mathrm{H}_{11}\right]^{+}(73.33), 57\left[\mathrm{C}_{4} \mathrm{H}_{9}\right]^{+}(100) .\end{array}$ \\
\hline $\begin{array}{l}\text { 3-hydroxy-2- } \\
\text { methylpropyl } \\
\text { palmitate }\end{array}$ & $\begin{array}{l}328[\mathrm{M}]^{+}(4.44), 313\left[\mathrm{C}_{19} \mathrm{H}_{37} \mathrm{O}_{3}\right]^{+}(19.78), 300\left[\mathrm{C}_{18} \mathrm{H}_{36} \mathrm{O}_{3}\right]^{+}(3.33), 285\left[\mathrm{C}_{17} \mathrm{H}_{33} \mathrm{O}_{3}\right]^{+}(2.22), 269 \\
{\left[\mathrm{C}_{17} \mathrm{H}_{33} \mathrm{O}_{2}\right]^{+}(1.11), 256\left[\mathrm{C}_{15} \mathrm{H}_{28} \mathrm{O}_{3}\right]^{+}(2.22), 213\left[\mathrm{C}_{12} \mathrm{H}_{21} \mathrm{O}_{3}\right]^{+}(13.33), 201\left[\mathrm{C}_{11} \mathrm{H}_{21} \mathrm{O}_{3}\right]^{+}(3.33), 185} \\
{\left[\mathrm{C}_{10} \mathrm{H}_{17} \mathrm{O}_{3}\right]^{+}(4.44), 156\left[\mathrm{C}_{11} \mathrm{H}_{24}\right]^{+}(17.78), 145\left[\mathrm{C}_{7} \mathrm{H}_{13} \mathrm{O}_{3}\right]^{+}(15.56), 127\left[\mathrm{C}_{9} \mathrm{H}_{19}\right]^{+}(52.22), 117} \\
{\left[\mathrm{C}_{5} \mathrm{H}_{9} \mathrm{O}_{3}\right]^{+}(44.44), 99\left[\mathrm{C}_{7} \mathrm{H}_{15}\right]^{+}(34.44), 73\left[\mathrm{C}_{4} \mathrm{H}_{9} \mathrm{O}\right]^{+}(51.11), 57\left[\mathrm{C}_{4} \mathrm{H}_{9}\right]^{+}(100) .}\end{array}$ \\
\hline 1-monolinolenin & $\begin{array}{l}352\left[\mathrm{MU}^{+}(0.44), 313\left[\mathrm{C}_{18} \mathrm{H}_{33} \mathrm{O}_{4}\right]^{+}(20), 297\left[\mathrm{C}_{17} \mathrm{H}_{29} \mathrm{O}_{4}\right]^{+}(1.11), 281\left[\mathrm{C}_{16} \mathrm{H}_{25} \mathrm{O}_{4}\right]^{+}(2.44), 257\right. \\
{\left[\mathrm{C}_{14} \mathrm{H}_{25} \mathrm{O}_{4}\right]^{+}(2.44), 207\left[\mathrm{C}_{15} \mathrm{H}_{27}\right]^{+}(4.44), 191\left[\mathrm{C}_{14} \mathrm{H}_{23}\right]^{+}(2.22), 189\left[\mathrm{C}_{9} \mathrm{H}_{17} \mathrm{O}_{4}\right]^{+}(2.22), 177\left[\mathrm{C}_{13} \mathrm{H}_{21}\right]^{+}} \\
(3.33), 163\left[\mathrm{C}_{12} \mathrm{H}_{19}\right]^{+}(4.67), 135\left[\mathrm{C}_{10} \mathrm{H}_{15}\right]^{+}(19.78), 117\left[\mathrm{C}_{4} \mathrm{H}_{5} \mathrm{O}_{4}\right]^{+}(47.11), 109\left[\mathrm{C}_{8} \mathrm{H}_{13}\right]^{+}(22.22), \\
95\left[\mathrm{C}_{7} \mathrm{H}_{11}\right]^{+}(55.56), 79\left[\mathrm{C}_{6} \mathrm{H}_{7}\right]^{+}(68.89), 67\left[\mathrm{C}_{5} \mathrm{H}_{7}\right]^{+}(75.56), 55\left[\mathrm{C}_{4} \mathrm{H}_{7}\right]^{+}(100) .\end{array}$ \\
\hline
\end{tabular}




\begin{tabular}{|c|c|}
\hline $\begin{array}{l}\text { 2,3-dihydroxypropyl } \\
\text { octadecanoate }\end{array}$ & $\begin{array}{l}358[\mathrm{M}]^{+}(0.44), 340\left[\mathrm{C}_{21} \mathrm{H}_{40} \mathrm{O}_{3}\right]^{+}(8.89), 327\left[\mathrm{C}_{20} \mathrm{H}_{39} \mathrm{O}_{3}\right]^{+}(1.11), 297\left[\mathrm{C}_{19} \mathrm{H}_{37} \mathrm{O}_{2}\right]^{+}(2), 285 \\
{\left[\mathrm{C}_{16} \mathrm{H}_{29} \mathrm{O}_{4}\right]^{+}(15.55), 267\left[\mathrm{C}_{18} \mathrm{H}_{35} \mathrm{O}\right]^{+}(11.11), 241\left[\mathrm{C}_{17} \mathrm{H}_{37}\right]^{+}(4.44), 227\left[\mathrm{C}_{16} \mathrm{H}_{35}\right]^{+}(2.22), 213} \\
{\left[\mathrm{C}_{15} \mathrm{H}_{33}\right]^{+}(2.44), 199\left[\mathrm{C}_{14} \mathrm{H}_{31}\right]^{+}(3.33), 185\left[\mathrm{C}_{13} \mathrm{H}_{29}\right]^{+}(11.11), 171\left[\mathrm{C}_{12} \mathrm{H}_{27}\right]^{+}(4.66), 157\left[\mathrm{C}_{11} \mathrm{H}_{25}\right]^{+}} \\
\left.(6.44), 129\left[\mathrm{C}_{9} \mathrm{H}_{21}\right]^{+}(37.77), 117\left[\mathrm{C}_{4} \mathrm{H}_{7} \mathrm{O}_{4}\right]^{+}(25.55), 97\left[\mathrm{C}_{7} \mathrm{H}_{13}\right]^{+}(33.33), 85\left[\mathrm{C}_{6} \mathrm{H}_{13}\right]^{+}(43.33)\right), 73 \\
{\left[\mathrm{C}_{5} \mathrm{H}_{13}\right]^{+}(78.88), 55\left[\mathrm{C}_{4} \mathrm{H}_{7}\right]^{+}(100) .}\end{array}$ \\
\hline squalene & $\begin{array}{l}410[\mathrm{M}]^{+}(1.66), 355\left[\mathrm{C}_{26} \mathrm{H}_{43}\right]^{+}(0.33), 341\left[\mathrm{C}_{25} \mathrm{H}_{41}\right]^{+}(3.33), 273\left[\mathrm{C}_{20} \mathrm{H}_{33}\right]^{+}(0.33), 207\left[\mathrm{C}_{15} \mathrm{H}_{27}\right](5), \\
191\left[\mathrm{C}_{14} \mathrm{H}_{23}\right]^{+}(3.33), 136\left[\mathrm{C}_{10} \mathrm{H}_{16}\right]^{+}(15), 123\left[\mathrm{C}_{9} \mathrm{H}_{15}\right]^{+}(10), 83\left[\mathrm{C}_{6} \mathrm{H}_{11}\right]^{+}(60), 69\left[\mathrm{C}_{5} \mathrm{H}_{9}\right]^{+}(100), 55 \\
{\left[\mathrm{C}_{4} \mathrm{H}_{7}\right]^{+}(8.33) .}\end{array}$ \\
\hline campesterol & $\begin{array}{l}400[\mathrm{M}]^{+}(100), 382\left[\mathrm{C}_{28} \mathrm{H}_{46}\right]^{+}(46.66), 357\left[\mathrm{C}_{25} \mathrm{H}_{41} \mathrm{O}\right]^{+}(5), 340(10), 315\left[\mathrm{C}_{22} \mathrm{H}_{35} \mathrm{O}\right]^{+}(60), 289 \\
(58.33), 273\left[\mathrm{C}_{19} \mathrm{H}_{29} \mathrm{O}\right]^{+}(26.66), 161(40), 145(53.33), 123(20), 107(63.33), 81(60), 71\left[\mathrm{C}_{5} \mathrm{H}_{11}\right]^{+} \\
(46.66), 55\left[\mathrm{C}_{4} \mathrm{H}_{7}\right]^{+}(66.66) .\end{array}$ \\
\hline$\beta$-sitosterol & $\begin{array}{l}414[\mathrm{M}]^{+}(100), 396(46.66), 371\left[\mathrm{C}_{26} \mathrm{H}_{43} \mathrm{O}\right]^{+}(3.33), 354(10), 329\left[\mathrm{C}_{23} \mathrm{H}_{37} \mathrm{O}\right]^{+}(56.66), 315 \\
{\left[\mathrm{C}_{22} \mathrm{H}_{35} \mathrm{O}\right]^{+}(3.33), 303\left[\mathrm{C}_{21} \mathrm{H}_{35} \mathrm{O}\right]^{+}(50), 273\left[\mathrm{C}_{19} \mathrm{H}_{29} \mathrm{O}\right]^{+}(30), 255(33.33), 247\left[\mathrm{C}_{17} \mathrm{H}_{27} \mathrm{O}\right]^{+}(5), 231} \\
(21.66), 170\left[\mathrm{C}_{12} \mathrm{H}_{26}\right](16.66), 81(56.66), 55\left[\mathrm{C}_{4} \mathrm{H}_{7}\right]^{+}(58.33) .\end{array}$ \\
\hline $\begin{array}{l}\text { 9,19-cyclolanost-24- } \\
\text { en-3-ol }\end{array}$ & $\begin{array}{l}426[\mathrm{M}]^{+}(10), 411\left[\mathrm{C}_{29} \mathrm{H}_{47} \mathrm{O}\right]^{+}(23.33), 393(41.66), 375\left[\mathrm{C}_{25} \mathrm{H}_{41} \mathrm{O}\right]^{+}(3.33), 365(25), 343 \\
{\left[\mathrm{C}_{24} \mathrm{H}_{39} \mathrm{O}\right]^{+}(3.33), 339(11.66), 315\left[\mathrm{C}_{22} \mathrm{H}_{35} \mathrm{O}\right]^{+}(3.66), 286(33.33), 273\left[\mathrm{C}_{19} \mathrm{H}_{29} \mathrm{O}\right]^{+}(20), 231(10),} \\
207\left[\mathrm{C}_{14} \mathrm{H}_{23} \mathrm{O}\right]^{+}(20), 109\left[\mathrm{C}_{8} \mathrm{H}_{13}\right]^{+}(56.66), 95(70), 83\left[\mathrm{C}_{6} \mathrm{H}_{11}\right]^{+}(48.33), 69\left[\mathrm{C}_{5} \mathrm{H}_{9}\right]^{+}(100), 55\left[\mathrm{C}_{4} \mathrm{H}_{7}\right]^{+} \\
(56.66) .\end{array}$ \\
\hline 3-ethylcyclohexene & $110[\mathrm{M}]^{+}(0.67), 95\left[\mathrm{C}_{7} \mathrm{H}_{11}\right]^{+}(10), 81\left[\mathrm{C}_{6} \mathrm{H}_{9}\right]^{+}(100), 67\left[\mathrm{C}_{5} \mathrm{H}_{7}\right]^{+}(33.33), 55\left[\mathrm{C}_{4} \mathrm{H}_{7}\right]^{+}(21.66)$ \\
\hline selegiline & $187[\mathrm{M}]^{+}(0.67), 96\left[\mathrm{C}_{6} \mathrm{H}_{10} \mathrm{~N}\right]^{+}(100), 91\left[\mathrm{C}_{7} \mathrm{H}_{7}\right]^{+}(10), 77\left[\mathrm{C}_{6} \mathrm{H}_{5}\right]^{+}(1.67), 56\left[\mathrm{C}_{4} \mathrm{H}_{8}\right]^{+}(13.33)$. \\
\hline
\end{tabular}




\section{EXPERIMENTAL}

3.1 GC/MS: Method 1: GC/MS analysis was performed at Agriculture Research Center, National Research Center, NRC, Dokki, Cairo, Egypt, on Aglient 6890 gas chromatograph equipped with an Aglient mass spectrometric detector, with a direct capillary interface and fused silica capillary column HP-5ms $(30 \mathrm{~m} \times 0.32 \mathrm{~mm} \times 0.25 \mu \mathrm{m}$ film thickness). Helium was used as carrier gas at approximately $1.0 \mathrm{ml} / \mathrm{mim}$, pulsed splitess mode. The solvent delay was $3 \mathrm{~min}$ and the injection size was $1.0 \mu \mathrm{l}$. The mass spectrometric detector was operated in electron impact ionization mode with an ionizing energy of $70 \mathrm{eV}$., scanning from $\mathrm{m} / \mathrm{z} 50$ to 500 . The ion source temperature was $230^{\circ} \mathrm{C}$. The electron multiplier voltage (EM voltage) was maintained at $1250 \mathrm{~V}$ above auto tune. The instrument was manually tuned using perfluorotributyl amine (PFTBA). The GC temperature program was started at $60^{\circ} \mathrm{C}(2 \mathrm{~min})$ then elevated to $280^{\circ} \mathrm{C}$ at a rate of $8^{\circ} \mathrm{C} / \mathrm{min}$. The detector and injector temperature were set at 300 and $280^{\circ} \mathrm{C}$, respectively. Wiley and Wiley Nist mass spectral data base was used in the identification of separated peaks; Method 2: GC/MS analysis was performed at National Research Center (NRC), Dokki, Cairo on a varian GC interfaced to Finnigan SSQ 7000 Mass Selective Detector (MSD) with ICIS V2.0 data system for MS identification of the GC components. The column used was DB-5 (J \& W Scientific, Folosm, CA) cross-linked fused silica capillary column (30 m long, $0.25 \mathrm{~mm}$ internal diameter) coated with polydimethylsiloxane $\quad(0.5 \mu \mathrm{m} \quad$ film thickness). The oven temperature was programmed from $50^{\circ} \mathrm{C}$ for $3 \mathrm{~min}$., at isothermal, then heating by $7^{\circ} \mathrm{C} / \mathrm{min}$. to $250^{\circ} \mathrm{C}$ and isothermally for $10 \mathrm{~min}$., at $250^{\circ} \mathrm{C}$. Injector temperature was $200^{\circ} \mathrm{C}$ and the volume injected was $0.5 \mu \mathrm{l}$. Transition line and ion source temperature were $250^{\circ} \mathrm{C}$ and $150^{\circ} \mathrm{C}$ respectively. The mass spectrometer had a delay of $3 \mathrm{~min}$. to avoid the solvent peak and then scanned from $\mathrm{m} / \mathrm{z} 50$ to $\mathrm{m} / \mathrm{z}$ 300. Ionization energy was set at $70 \mathrm{eV}$.

\subsection{Materials and Reagents}

Solvents: petroleum ether (60-80), diethyl ether, hexane, methylene chloride, ethyl acetate, acetone, butanol and methanol were obtained from Adwic Company; Chemical reagents for cytotoxicity activity: The cell lines HePG-2, hepatocellular carcinoma (liver) and MCF7 mammary gland (breast), were obtained from ATCC via Holding company for biological products and vaccines (VACSERA), Cairo, Egypt; RPMI-1640 medium, MTT, DMSO and 5-fluorouracil were obtained from Sigma co., St. Louis, USA; fetal bovine serum was obtained from GIBCO, UK; Chromatographic materials: preparative (PTLC) was performed on silica gel (Kieselgel 60, GF 254) of 0.25 thickness; Materials for nanoparticle formulation: poly (ethylene glycol)-block-Poly (propylene glycol)block- Poly (ethylene glycol) [Pluronic F108] and acetone were provided by Aldrich (Germany). All the other chemical reagents were of analytical grade.

\subsection{Plant material}

Flaxseed (Linum usitatissimum) was purchased from local market, Mansoura city, Egypt, in January 2014.

\subsection{Processing of the plant material}

Flaxseed was grinded to give a dried powder material (350 g), which was extracted by a soxhlet extractor using different solvents; $n$-hexane, methylene chloride and methanol, respectively to obtain three fractions; hexane fraction, Lu1 (118.2 g, 33.771\% w/w), methylene chloride fraction, Lu2 (20 g, 5.714\% w/w) and methanol fraction, Lu3 (47 g, 13.428\% $\mathrm{w} / \mathrm{w})$. The methylene chloride fraction, Lu2 was defatted with cold methanol to give defatted material. The methanol fraction, Lu3 was hydrolyzed at room temperature with $1 \mathrm{M} \mathrm{NaOH}$ for $12 \mathrm{~h}$, then the solution was neutralized with $0.1 \mathrm{HCl}$ then extracted by hexane, methylene chloride, ethyl acetate and butanol using a separatory funnel to give the subfractions hexane (Lu3a, $1.142 \mathrm{~g}$ ), methylene chloride 
(Lu3b, $1.993 \mathrm{~g}$ ), ethyl acetate (Lu3c, 1.600 g) and butanol (Lu3d, $1.200 \mathrm{~g}$ ), respectively.

GC/MS analysis of hexane fraction (Lu1): A sample of hexane extract (Lu 1) was analyzed using GC/MS analysis method 1 to afford 2,4-heptadienal (Rt 7.17 min., $0.17 \%)$, dodecane ( $R_{t} 11.20$ min., $\left.0.05 \%\right)$, 2-decenal $\left(R_{\mathrm{t}} 12.37\right.$ min., $\left.0.06 \%\right)$, 3ethylcyclohexene ( $R_{t} 13.37$ min., $\left.0.20 \%\right)$, tetradecane $\left(R_{t} 14.70\right.$ min., $\left.0.04 \%\right)$, selegiline $\left(R_{t} 15.36\right.$ min., $\left.0.56 \%\right)$, pentadecanoic acid ( $R_{t} 21.44$ min., 0.07\%), hexadecanoic acid ( $R_{t} 23.08$ min., 10.69\%), 9,17-octadecadienal ( $R_{\mathrm{t}} 23.72 \quad \mathrm{~min}$., $0.09 \%)$, heptadecanoic acid $\left(R_{t} 23.93\right.$ min., $0.06 \%)$, linoleic acid ( $R_{t} 24.23$ min., $\left.0.07 \%\right)$, methyl $(\mathrm{Z}, \mathrm{Z}, \mathrm{Z}) 9,12,15$-octadecatrienoate $\left(R_{t} \quad 24.31\right.$ min., 0.13\%), (Z,Z) 9,12octadecadienoic acid $\left(R_{\mathrm{t}} 24.55\right.$ min., 0.35\%), 9,12,15-octadecatrien-1-ol $\quad\left(R_{t}\right.$ 24.69 min., $0.49 \%), \quad 9,12,15-$ octadecatrienoic acid $\left(R_{\mathrm{t}} 25.97\right.$ min., $80.97 \%)$, eicosane ( $R_{t} 29.90$ min., $\left.0.07 \%\right)$, octacosane $\left(R_{\mathrm{t}} 30.93\right.$ min., $\left.0.08 \%\right)$, squalene ( $R_{t} \quad 31.66$ min., $\left.0.09 \%\right)$, nonacosane $\left(R_{t} \quad 32.07\right.$ min., $\left.0.08 \%\right)$, triacontane $\left(R_{\mathrm{t}} \quad 33.37\right.$ min., $\left.0.08 \%\right)$, campesterol ( $R_{\mathrm{t}} 37.85$ min., 0.16\%), sitosterol $\left(R_{t} 39.90\right.$ min., $\left.0.25 \%\right)$ and 9,19cyclolanost-24-en-3-ol $\left(R_{t} 41.85\right.$ min., $0.34 \%)$.

GC/MS analysis of methylene chloride fraction (Lu2): A sample of methylene chloride fraction ( Lu 2) was analyzed using GC/MS analysis method 1 to afford hexadecane $\left(R_{t} 31.28\right.$ min., $\left.0.87 \%\right)$, heptadecane $\left(R_{t} 34.05\right.$ min., $\left.0.84 \%\right)$, octadecane ( $R_{t} 36.66$ min., 1.15\%), methyl palmitate ( $R_{t} 39.88$ min., 6.19\%), eicosane $\left(R_{t} \quad 41.54\right.$ min., 1.14\%), 3-hydroxy-2methylpropylpalmitate $\left(R_{t} 43.24\right.$ min., $0.54 \%)$, 1-monolinolenin ( $R_{t} 43.45$ min., 0.77\%), methyl,9-cis,11-transoctadecadienoate ( $R_{t} 43.79$ min., 7.69\%), methyl $(\mathrm{Z}, \mathrm{Z}, \mathrm{Z}) 9,12,15$-octadecatrienoate $\left(R_{t} \quad 43.95\right.$ min., 32.01\%), methyl octadecanoate ( $R_{t} 44.51$ min., $\left.1.88 \%\right)$, butyl hexadecanoate $\left(R_{t} 45.77\right.$ min., $\left.2.88 \%\right)$, tetracosane ( $R_{t} 46.01$ min., $\left.0.92 \%\right), 2,3-$ dihydroxypropyl hexadecanoate $\left(R_{t} 48.11\right.$ min., 0.65\%), butyl 9,12-octadecadienoate $\left(R_{t} \quad 49.29\right.$ min., $2.45 \%$ ), buty, $9,12,15-$ octadecatrienoate ( $R_{t} 49.46$ min., $\left.16.29 \%\right)$, 2,3-dihydroxypropyl octadecanoate $R_{t} 49.93$ min., $0.80 \%)$, tetracosane $\left(R_{t} 50.13\right.$ min., $1.19 \%)$, pentacosane $\left(R_{t} 52.07\right.$ min., $0.94 \%)$, hexacosane ( $\left.R_{t} 53.94 \mathrm{~min} ., 1.16 \%\right)$, heptacosane $\left(R_{\mathrm{t}} 55.94\right.$ min., $\left.1.29 \%\right)$, octacosane $\left(R_{t} \quad 57.48\right.$ min., $\left.1.37 \%\right)$, nonacosane $\left(R_{t} 59.17\right.$ min., $\left.0.98 \%\right)$, triacontane ( $R_{t} 60.80$ min., $\left.0.73 \%\right)$ and hentriacontane ( $R_{t} 62.38$ min., 0.61\%).

\section{GC/MS analysis of hexane subfraction Lu} 3a: A sample of hexane subfraction (Lu 3a) was analyzed using GC/MS analysis method 2 to afford methyl-9-oxononanoate $\left(R_{t} 26.61\right.$ min., $\left.0.71 \%\right)$, cetene $\left(R_{t} \quad 31.10 \quad\right.$ min., $\left.0.25 \%\right)$, methyl tetradecanoate $\left(R_{t} 34.83\right.$ min., $\left.0.49 \%\right)$, 1octadecene ( $R_{t} 36.54$ min., $\left.0.30 \%\right)$, methyl pentadecanoate $\left(R_{t} 37.45\right.$ min., $\left.0.40 \%\right)$, methyl palmitate ( $R_{t} 40.37$ min., 38.64\%), methyl 14-methylhexadecanoate $\left(R_{t} 42.36\right.$ min., $0.28 \%)$, hexadecanoic acid $\left(R_{\mathrm{t}} 42.73\right.$ min., $\quad 0.50 \%)$, methyl $(Z, Z) 9,12-$ octadecadienoate( $R_{t} 43.73$ min., $\left.1.75 \%\right)$, methyl (Z,Z)8,11-octadecadienoate $\left(R_{t}\right.$ 43.86 min., $0.59 \%)$, methyl $(Z, Z) 7,10$ methyloctadecadienoate $\left(R_{\mathrm{t}} 44.37\right.$ min., 9.91\%), methyl (Z,Z,Z)9,12,15octadecatrienoate ( $R_{t} 45.00$ min., $\left.5.36 \%\right)$, methyl octadecanoate $\left(R_{t} 45.16\right.$ min., 9.85\%), (Z,Z)9,12-octadecadienoic acid $\left(R_{t}\right.$ 46.38 min., $4.16 \%)$, methyl-9-eicosenoate $\left(R_{t} 48.38\right.$ min., $\left.0.57 \%\right)$, methyl eicosanoate $\left(R_{t} \quad 48.90 \quad\right.$ min., $\left.0.40 \%\right)$, methyl docosanoate $\left(R_{t} 52.80\right.$ min., $\left.0.41 \%\right)$, methyl tricosanoate ( $R_{t} 54.63$ min., $\left.0.22 \%\right)$ and methyl tetracosanoate ( $R_{\mathrm{t}} 56.44 \mathrm{~min}$., $0.62 \%)$.

GC/MS analysis of methylene chloride subfraction Lu 3b: A sample of methylene chloride subfraction (Lu 3b) was analyzed using GC/MS analysis method 2 to afford eicosane ( $R_{t} 15.10$ min., 0.61\%), 2-methyleicosane ( $\left.R_{t} 16.76 \mathrm{~min}, 0.15 \%\right)$, henicosane $\left(R_{t} 17.33 \mathrm{~min}, 0.41 \%\right)$, docosane $\left(R_{t} 19.47\right.$ min, $0.49 \%)$, tricosane $\left(R_{t} 21.55 \mathrm{~min}\right.$, $0.22 \%)$, tetracosane $\left(R_{t} 23.56 \mathrm{~min}, 0.81 \%\right)$, 
pentacosane (Rt $25.48 \mathrm{~min}, \quad 0.32 \%$ ), hexacosane $\left(R_{\mathrm{t}} 27.34 \mathrm{~min}, 0.54 \%\right)$, heptacosane $\left(R_{t} 29.14 \mathrm{~min}, 0.30 \%\right)$, octacosane $\left(R_{t} \quad 30.88 \mathrm{~min}, 0.40 \%\right)$, nonacosane $\left(R_{t} \quad 32.57 \mathrm{~min}, 0.24 \%\right)$, triacontane $\left(R_{t} \quad 34.19 \mathrm{~min}, 0.22 \%\right)$, hentriacontane $\left(R_{t} 35.77 \mathrm{~min}, 0.15 \%\right)$ and dotriacontane ( $\left.R_{\mathrm{t}} 37.33 \mathrm{~min}, 0.10 \%\right)$.

Chromatographic separation trials of subfractions (hexane, methylene chloride and ethyl acetate) didn't give pure compounds.

The subfraction (Lu 3d, 1.200g) was subjected to silica gel CC using ethyl acetate/methanol as an eluent with gradient increasing polarity. The eluted fractions were monitored and collected based on their TLC patterns. The fraction eluted by ethyl acetate /methanol 7:3 $(0.120 \mathrm{~g})$ was reseparated on a sephadex LH-20 CC (methylene chloride/methanol, 1:9) to give ${ }^{-5} 5^{\prime}$ neolignan (dehydrodiconiferyl alcohol-4- $\beta-D-$ glucoside 1, $55 \mathrm{mg}$ ).

\subsection{Preparation of butanol subfracrion Lu 3d-loaded pluronic nano-micelles}

Lu 3d-loaded pluronic nano-micelles were prepared via nanoprecipitation method. The used polymer: Lu $3 d$ ratio was $2: 1$. In brief, $124 \mathrm{mg}$ of pluronic and $62 \mathrm{mg}$ of the the $\mathrm{Lu} 3 \mathrm{~d}$ were dissolved in $15 \mathrm{ml}$ acetone (95\%) to prepare the organic phase. After complete dissolution of the organic phase, it was added dropwise with sonication into $30 \mathrm{ml}$ of distilled water. The final suspension was left to allow the evaporation of acetone and a water portion to form a concentrated nanosuspension. Finally, the obtained nanosuspension was lyophilized in a Labconco freeze dryer to obtain dried nanoparticles powder. Plain pluronic nanoparticles were prepared by the same method as control. The entrapment efficiency (EE\%) of the loaded Lu 3d was determined by centrifugation of a certain volume of the nanoparticles suspension at a speed of $24,000 \mathrm{rpm}$ with cooling. Then, the amounts of the unloaded $L u 3 d$ remaining free in the supernatant were determined using UV-Vis spectrophotometry at the optimum wavelengths. Afterwards, the amount of the Lu $3 d$ loaded into the nanoparticles was obtained by knowing the initial added amount of the Lu $3 \mathrm{~d}$. The mean value from three replicates \pm SD was obtained. The entrapment efficiency ( $E E \%$ ) of the Lu 3d was calculated according to the following relationship:

$$
E E \%=\left(\frac{m r}{m i}\right) \times 100
$$

Where $m_{i}$ and $m_{r}$ are the amounts (mg) of the bioactive compound initially loaded and remained in the nanoparticles, respectively.

\subsection{Determination of particle size and zeta potential}

The size and the zeta potential of the prepared plain and Lu $3 d$-loaded pluronic nanoparticles were estimated at $\lambda_{\max }$ of $480 \mathrm{~nm}$ using dynamic light scattering, DLS (Malvern nanosizer, Malvern Instruments Ltd., Worcestershire, UK) with a refractive index of 1.363 for the solvent.

\subsection{Surface morphology}

The morphology of the developed pluronic nanoparticles was examined by the transmission electron microscopy (TEM, JEOL, JEM-1230, Japan Ltd.) at an accelerating voltage of $200 \mathrm{kV}$. Samples were prepared for the imaging via drying the nanoparticles on a copper grid that is coated with a thin layer of carbon.

\subsection{In-vitro enzymatic degradation study}

An in-vitro degradation study of the developed pluronic nanoparticles was carried out in presence of lysozyme (1.5 
$\mathrm{mg} / \mathrm{ml}$ PBS, $\mathrm{pH}$ 7.4). A certain weight $\left(W_{0}\right)$ of the nanoparticles (10-15 mg) was transferred to microcentrifuge tube and incubated with $0.8 \mathrm{ml}$ of lysozyme solution at $37^{\circ} \mathrm{C}$ in a shaking incubator at $120 \mathrm{rpm}$ (VWR $^{\circ}$ incubating orbital shaker, VWR International, Brisbane, CA, USA) for 60 $\min$. The samples were then centrifuged for $2 \mathrm{~min}$ at speed of $14000 \mathrm{rpm}$ and the final weight of the nanoparticles $\left(W_{t}\right)$ was determined after discarding the supernatant. Afterward, a fresh lysozyme solution $(0.8 \mathrm{ml})$ was added to the nanoparticles. At certain intervals, the steps of centrifugation and weighing were repeated and the final weights $\left(W_{t}\right)$ of nanoparticles at these intervals were determined. The percent weight remaining $\left(W_{r} \%\right)$ of the samples due to enzymatic degradation were calculated according to the following relationship:

$$
W_{r}(\%)=100-\left(\frac{\left(W_{0}-W_{t}\right)}{W_{0}} \times 100\right)
$$

Where $W_{0}$ and $W_{t}$ are the initial weight of sample, and after incubation with lysozyme for a given time, $t$, respectively.

\subsection{In-vitro release studies}

The in-vitro release pattern of the loaded Lu $3 d$ from the pluronic nanoparticles was determined by transferring certain amounts (20-25 mg) of the Lu 3d-loaded nanoparticles to scintillation vials containing $10 \mathrm{ml}$ of PBS, $\mathrm{pH}$ 7.4. The samples were maintained at $37^{\circ} \mathrm{C}$ in a shaking incubator at $120 \mathrm{rpm}\left(\mathrm{VWR}^{\circ}\right.$ incubating orbital shaker, VWR International, Brisbane, CA, USA). At predetermined intervals, $1 \mathrm{ml}$ aliquots were withdrawn and diluted with an equal volume of ethanol and then analyzed at the optimum $\lambda_{\max }$ with the aid of UV-Vis spectrophotometer. The withdrawn aliquots were replaced with equal volumes of fresh PBS, 7.4 buffer, to keep the volume of release medium constant. The amounts of bioactive compounds released $(\mu \mathrm{g})$ from the pluronic nanoparticles were calculated with the aid of a standard curve in PBS, pH 7.4/ethanol (1:1). The obtained results were calculated in terms of cumulative release $(\%, \mathrm{w} / \mathrm{w})$ relative to the already entrapped weight of the Lu $3 d$ in the nanoparticles. The collected data represents mean \pm SD from three independent release experiments.

\subsection{Statistical analysis}

The obtained data was analyzed and expressed as mean \pm SD. The effect of various parameters on the characteristics of the prepared pluronic nanoparticles were statistically analyzed by one-way ANOVA using Excel (Microsoft Office 2007). Differences were considered significant at the level of $p<0.05$.

\subsection{Antimicrobial activity assessment}

Chemical compounds were individually tested against Staphylococcus aureus, as a Gram positive bacterium, Escherichia coli, as a Gram negative bacterium and Candida albicans, as a fungi. Each of the compounds was dissolved in DMSO and solutions of the concentration $1 \mathrm{mg} / \mathrm{ml}$ were prepared. Paper discs of Whatman filter paper with standard size $(5 \mathrm{~mm})$ were cut and sterilized in an autoclave. The paper discs were soaked in the desired concentration of the complex solution and places aseptically in the Petri-dishes containing nutrient agar media (agar 20g + beef extract $3 \mathrm{~g}+$ peptone $5 \mathrm{~g}$ ) seeded with Staphylococcus aureus, E. coli and Candida albicans. The Petri-dishes were incubated at $36^{\circ} \mathrm{C}$ and the inhibition zones were recorded after $24 \mathrm{~h}$ of incubation. Each treatment was replicated three times. The antibacterial activity of a common standard antibiotic, Ampicillin, and antifungal, Colitrimazole, was also recorded using the same procedure as above at the same concentration and solvents. The $\%$ activity index for the complex was calculated by the formula as under:

$\%$ Actiity Index $=\frac{\text { Zone of inhibition by test extract (diametre) }}{\text { Zone of inhibition by standard (diametre) }} \mathbf{X} 100$ 


\subsection{Antioxidant activity assessment}

For each of the investigated compounds ( 2 $\mathrm{mL}$ ) of ABTS solution $(60 \mu \mathrm{M})$ was added to $3 \mathrm{~mL} \mathrm{MnO}_{2}$ solution $(25 \mathrm{mg} / \mathrm{mL})$, all prepared in $(5 \mathrm{~mL})$ aqueous phosphate buffer solution ( $\mathrm{pH} 7,0.1 \mathrm{M})$. The mixture was shaken, centrifuged, filtered and the absorbance of the resulting green blue solution (ABTS radical solution) at $734 \mathrm{~nm}$ was adjusted to approx. ca. 0.5 . Then, $50 \mu \mathrm{l}$ of $(2 \mathrm{mM}$ ) solution of the tested compound in spectroscopic grade $\mathrm{MeOH} /$ phosphate buffer (1:1) was added. The absorbance was measured and the reduction in color intensity was expressed as inhibition percentage. L-ascorbic acid was used as standard antioxidant (Positive control). Blank sample was run without ABTS and using $\mathrm{MeOH} /$ phosphate buffer (1:1) instead of tested compounds. Negative control was run with ABTS and $\mathrm{MeOH} /$ phosphate buffer (1:1) only.

\subsection{Cytotoxicity assay}

The cell lines HePG-2 and MCF-7, were used to determine the inhibitory effects of extracts on cell growth using the MTT assay. This colorimetric assay is based on the conversion of the yellow tetrazolium bromide (MTT) to a purple formazan derivative by mitochondrial succinate dehydrogenase in viable cells. HepG2 was cultured in RPMI-1640 medium with 10\% fetal bovine serum. Antibiotics added were 100 units $/ \mathrm{ml}$ penicillin and $100 \mu \mathrm{g} / \mathrm{ml}$ streptomycin at $37^{\circ} \mathrm{C}$ in a $5 \% \quad \mathrm{CO}_{2}$ incubator. The cell line was seeded in a 96well plate at a density of $1.0 \times 10^{4}$ cells/well, at $37^{\circ} \mathrm{C}$ for $48 \mathrm{~h}$ under $5 \% \mathrm{CO}_{2}$. After incubation the cells were treated with different concentration of compounds and incubated for $24 \mathrm{~h}$. After $24 \mathrm{~h}$ of drug treatment, $20 \mu \mathrm{l}$ of MTT solution at 5 $\mathrm{mg} / \mathrm{ml}$ was added and incubated for $4 \mathrm{~h}$. Dimethyl sulfoxide (DMSO) in volume of $100 \mu \mathrm{l}$ is added into each well to dissolve the purple formazan formed. The colorimetric assay is measured and recorded at absorbance of $570 \mathrm{~nm}$ using a plate reader (EXL 800). The relative cell viability in percentage was calculated as:
Relative cell viability $=\left(\right.$ Absorbance $_{570}$ of treated samples/ Absorbance 570 of untreated sample) X 100.

\section{ACKNOWLEDGMENTS}

I wish to express my sincere appreciation and gratitude to Prof., Dr. Mamdouh Abdel-Mogib, Professor of Natural Products' Chemistry, Faculty of Science, Mansoura University, Egypt , for introducing me to the field of natural products his guidance, moral support, help, advice precious, Thanks to Dr. Ibrahim M. El-Sherbiny and Manal Gmal ElFedawy for their help.

I would like to express my gratitude and thanks to my father, mother and dear husband for supporting me.

\section{REFERENCES}

[1] Oomah, B. D., Flaxseed as a functional food source. Journal of the Science of Food and Agriculture, 81, 889-894, (2001).

[2] Flax A. B. and Fu, Y. B. Genetic evidence for early flax domestication with capsular dehiscence. Genetic Resources and Crop Evolution, 58, (8), (2011).

[3] Oomah, B. D., and Mazza, G. Bioactive components of flaxseed. Occurrence and health benefits. In F. Shahidi C. T. Ho (Eds.), Phytochemicals and phytopharmaceuticals, 105-120, (2000).

[4] Susheelamma, N. S. Functional role of linseed (Linum usitatissimum) polysaccharide in steamed pudding (idli). J. Food Sci. Techn, 26, 16-20, (1989).

[5] Song, Li; Wang, Xian-Fen; Wu, Yan; He, Wen-Yi; Yao, Chun-Suo; Shi, Jian-Gong, Chemical constituents from the linseed meal. Fitoterapia, 97, 15-22, (2014).

[6] Sheng-Xiang, Q.; Zhi-Zhen, L.; Lumonadio L.; Sang, K.; John M.; Norman, R.; Lilian U. and Harry, $H$. Fong1, Isolation and Characterization of Flaxseed (Linum Usitatissimum) Constituents. Pharm. Biology, 37, (1), 17, (1999). 
[7] Lucy, P.; Meagher, R.; Beecher, P.; Flanagan, I. and Betty, W., Isolation and Characterization of the Lignans, Isolariciresinol and Pinoresinol, in Flaxseed Meal. J. Agric. Food Chem, 47, (8), 3173-3180, (1999).

[8] Xiaoying, C. and Dong U., Antioxidant Activities of Six Natural Phenolics Against Lipid Oxidation Induced by $\mathrm{Fe} 2+$ or Ultraviolet Light. Journal of the American Oil Chemists Society, JAOCS, 75, (12), 1717-1721, (1998).

[9] Viorica-Mirela, P.; Alexandra G.; Dianaicoleta, R.; Delia, D.; Camelia, M. and Despina, B., Constantin Mateescu, Fatty acids composition and oil characteristics of linseed (Linum Usitatissimum L.) from Romania, Journal of Agroalimentary Processes and Technologies, 18, 136140, (2012).

[10] Kreuter, J. Nanoparticles. In: Kreuter J, editor. Colloidal Drug Delivery Systems, New York: Marcel Dekker; 219-342 (1994).

[11] Vickram, B.; Ophelia, F.; Christophe, H.; Serge, P.; Eric, G.; David, L.; Dominique, C.; Frederic, L. ; Eric, L.; Jose, K., Marc-Andre, F.; François, M.; Coniferin dimerisation in lignan biosynthesis in flax cells. Phytochemistry, 68, 2744-2752, (2007).

[12] Seifert, K.; Preiss, A.; Johne, S.; Schmidt, J.; Lien. N.; Lavaud, C. and Massiot, G., Triterpenesaponins from Verbascum songaricum. Phytochemistry, 30, 3395-3400, (1991).

[13] Lissi, E.; Modak, B.; Torres, R.; Escobar, J.; Urza, A., Free Radical Res, 30, 471 477, (1999).

[14] Mosad, A. ; Ghareeb, H. ; Hassan, M. ; Laila, A.; Refahy, M. and Amal, M., Antioxidant and cytotoxic activities of flavonoidal compounds from Gmelinaarborea (Roxb.). Global J. Pharm, 8, (1), 87-97, (2014).
[15] Ghareeb, M. A.; Hussein A. S.; Hassan M. F, Madkour, Laila A. Refahy, Mona A. Mohamed and Amal M. Saad. Radical scavenging potential and cytotoxic activity of phenolic compounds from Tectonagrandis (Linn.). Global J. Pharm, 7, (4), 486-497, (2013).

[16] Mauceri H, Hanna N, Beckett $M$, Gorski D, Staba M, Stellato K, Bigelow K, Heimann R, Gately S, Dhanabal M, SoffG $A$, Sukhatme $V$, Kufe $D$ and Weichselbaum R. Combined effects of agiostatin and ionizing radiation in antitumour therapy. Nature, 394, 287291, (1998). 